\title{
Performance Simulation Comparison for Parabolic Trough Solar Collectors in China
}

\author{
Jinping Wang, ${ }^{1,2,3}$ Jun Wang, ${ }^{1,3}$ Xiaolong $\mathrm{Bi}^{2}{ }^{2}$ and Xiang Wang ${ }^{2}$ \\ ${ }^{1}$ Jiangsu Provincial Key Laboratory of Solar Energy Science and Technology, School of Energy and Environment, \\ Southeast University, Nanjing 210096, China \\ ${ }^{2}$ School of Energy \& Power Engineering, Nanjing Institute of Technology, Nanjing 211167, China \\ ${ }^{3}$ College of Energy \& Environment Engineering, Southeast University, Nanjing 210096, China \\ Correspondence should be addressed to Jun Wang; 101010980@seu.edu.cn
}

Received 26 October 2015; Accepted 12 January 2016

Academic Editor: Jegadesan Subbiah

Copyright (C) 2016 Jinping Wang et al. This is an open access article distributed under the Creative Commons Attribution License, which permits unrestricted use, distribution, and reproduction in any medium, provided the original work is properly cited.

\begin{abstract}
Parabolic trough systems are the most used concentrated solar power technology. The operating performance and optical efficiency of the parabolic trough solar collectors (PTCs) are different in different regions and different seasons. To determine the optimum design and operation of the parabolic trough solar collector throughout the year, an accurate estimation of the daily performance is needed. In this study, a mathematical model for the optical efficiency of the parabolic trough solar collector was established and three typical regions of solar thermal utilization in China were selected. The performance characteristics of cosine effect, shadowing effect, end loss effect, and optical efficiency were calculated and simulated during a whole year in these three areas by using the mathematical model. The simulation results show that the optical efficiency of PTCs changes from 0.4 to 0.8 in a whole year. The highest optical efficiency of PTCs is in June and the lowest is in December. The optical efficiency of PTCs is mainly influenced by the solar incidence angle. The model is validated by comparing the test results in parabolic trough power plant, with relative error range of $1 \%$ to about $5 \%$.
\end{abstract}

\section{Introduction}

In recent years, concentrated solar power (CSP) for electricity production promises to be one of the most viable options to replace fossil fuel power plants [1]. Concentrated solar power (CSP) systems use optical devices (usually mirrors) and sun-tracking systems to concentrate a large area of sun light onto a smaller receiving area [2]. There are four available CSP technologies: (a) parabolic troughs, (b) solar dishes, (c) linear Fresnels, and (d) solar power towers [3]. China has announced plans to invest some CSPs projects in Qinghai, Tibet, Gansu, and other solar energy resource rich regions during the Twelfth and Thirteenth Five-Year Plan (2014-2020) [4]. Some of these projects are already under construction, such as the $50 \mathrm{MW}$ parabolic trough solar thermal power generation project in Delingha, Qinghai Province, and the $10 \mathrm{MW}$ solar thermal power generation project in Dunhuang, Gansu Province [5]. In the technology field of concentrated solar thermal power generation, parabolic trough solar collector (PTC) plants are the most developed ones of all commercially operating plants [6]. A parabolic trough consists of a linear parabolic mirror which reflects and concentrates the received solar energy onto a tube (receiver) positioned along the focal line $[7,8]$. PTCs can only use direct solar radiation, called beam radiation or Direct Normal Irradiance (DNI), that is, the beam that come directly from the solar disk but not those that could be reflected from the surroundings $[9,10]$.

To determine the optimum design and operation of the solar energy utilization technology throughout the year, an accurate estimation of the daily performance is essential. Over the years, several researchers had generated calculation procedures for obtaining synthetic data on a daily or hourly basis. Knight et al. [11] had carried out the models for generating hourly series of radiation and ambient temperature values, which aimed to replicate the statistics of long-term data with just one year of generated data. Petrakis et al. [12] predicted and compared the performance and costeffectiveness of passive and active solar systems in the island by means of Typical Meteorological Year of Nicosia, Cyprus, 


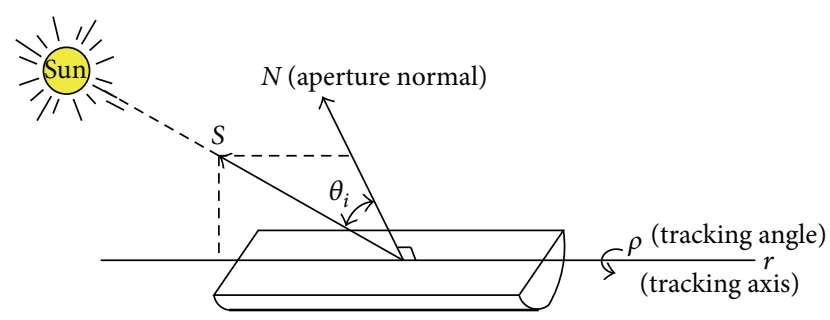

FIGURE 1: A single axis tracking aperture.

and then Florides et al. [13] analyzed the weather data contained in a Typical Meteorological Year (TMY) and observed the effect of these data on the simulated load of a typical building. García-Barberena et al. [14] evaluated the influence of operational strategies on the performance of parabolic trough solar power plants with the aid of a computer program for the simulation of the energy behavior of parabolic trough solar power plants. Bonilla et al. [15] established a dynamic simulator design and development of a direct steam generation parabolic trough solar thermal power plant. Wagner and Wittmann [16] researched the influence of different operation strategies on transient solar thermal power plant simulation models with molten salt as heat transfer fluid. Huang et al. [17] proposed a new analytical model of optical performance and a modified integration algorithm is proposed to simulate the performance of a parabolic trough solar collector with vacuum tube receiver. Zhang et al. [18] presented the baseline for performance and economic evaluation of solar thermal systems based on the site test data and related references.

The operating performance and optical efficiency of the parabolic trough solar collector are different in different regions and different seasons. The performance of PTCs is very important for the operation and parabolic trough solar power plants location choice. However, comparison analysis on the operation performance of the parabolic trough solar collectors in different regions was still relatively rare. In this study, a mathematical model for the optical efficiency of the parabolic trough solar collector was established; three typical regions of solar thermal utilization in China were selected. The operating characteristics of cosine effect, shadowing effect, end loss effect, and optical efficiency were calculated and simulated by using the mathematical model during a whole year in these three areas.

\section{Methodology}

2.1. Geometry Model for PTC. Parabolic trough solar collectors are designed to operate with tracking about only one axis. A tracking drive system rotates the collector about an axis of rotation until the sun central ray and the aperture normal area are coplanar. Figure 1 shows the angle of incidence between the collector normal and the beam radiation on a parabolic trough solar collector. The angle of solar incidence results from the relationship between the sun's position in the sky and the orientation of the collectors for a given location [19]. The angle of solar incidence is not equal to $0^{\circ}$ and the
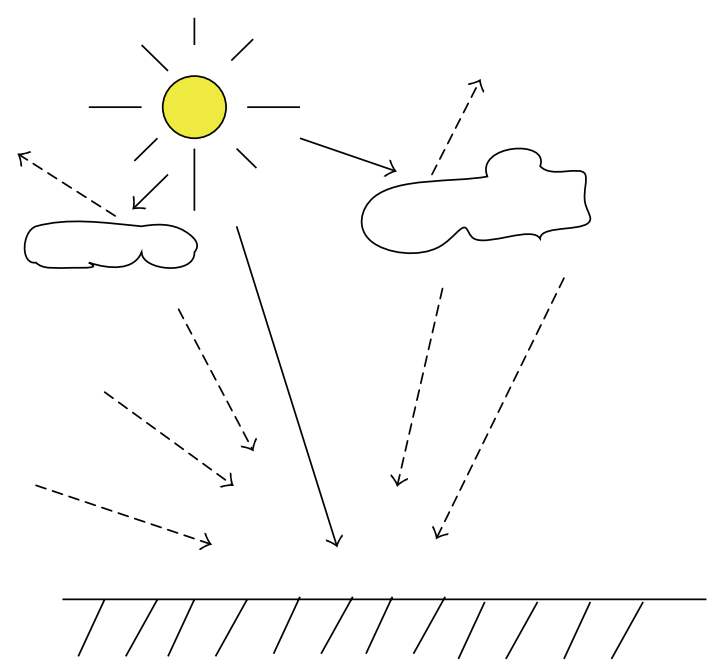

$\longrightarrow$ Direct normal radiation

$-\rightarrow$ Diffuse radiation

Figure 2: Direct and diffuse solar irradiation.

reason is that the parabolic trough solar collector is generally horizontal layout, single axis tracking the sun [20,21].

2.2. Mathematical Model of Total Optical Efficiency for PTC. Extraterrestrial solar radiation follows a direct line from the sun to the earth. Upon entering the earth's atmosphere, some solar radiation is diffused by air, water molecules, and dust within the atmosphere. The global solar irradiance over a horizontal surface that does not collect radiation due to reflection or diffusion is composed of the direct solar irradiance and the diffuse irradiance [22], as shown in Figure 2.

The relationship between the global solar irradiance, the direct solar irradiance, and the diffuse irradiance can be expressed as

$$
G_{h}=D_{h}+B_{h}
$$

where $B_{h}$ is direct horizontal radiation and $D_{h}$ is diffuse radiation.

As parabolic trough solar concentrators accept only DNI, diffuse irradiation is subtracted from the global irradiation to obtain the beam irradiation. So formula (1) can be further described as

$$
G_{h}=D_{h}+B_{n} A_{c} \cos \left(\theta_{i}\right),
$$

where $B_{n}$ is Direct Normal Irradiance (DNI), $\theta_{i}$ is the angle of solar incidence, and $A_{c}$ is the collector aperture area. Power absorbed by the receiver of a parabolic trough solar concentrator can be written as [23]

$$
\begin{aligned}
Q_{\mathrm{abs}}= & \eta_{\text {geo }} \cdot \eta_{\text {shadow }} \cdot \eta_{\text {endloss }} \cdot \eta_{\text {track }} \cdot \rho_{m} \cdot \eta_{\text {gen }} \cdot K \cdot \mathrm{Cl} \\
& \cdot A_{c} \cdot B_{n},
\end{aligned}
$$

where $\eta_{\text {geo }}$ is geometry effect; $\eta_{\text {shadow }}$ is the factor for solar shading; $\eta_{\text {endloss }}$ is the factor for the calculation of the relative 


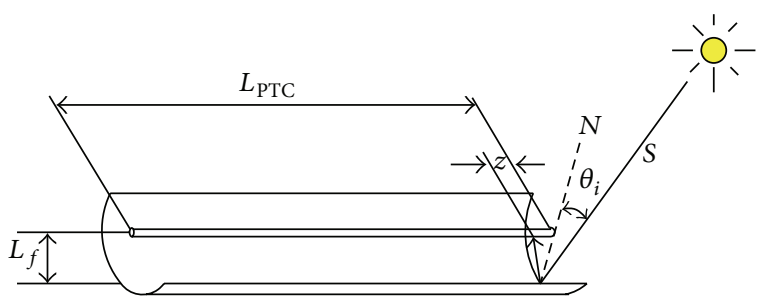

FIgure 3: End losses of a PTC.

end loss; $K$ is the Incident Angle Modifier; $\mathrm{Cl}$ is the mean cleanliness factor; $\rho_{m}$ is the mirror reflectance; $\eta_{\text {track }}$ is the tracking error; $\eta_{\text {gen }}$ is the general error.

The total optical efficiency for parabolic trough solar collector is defined:

$$
\begin{aligned}
\eta_{\text {opt }} & =\frac{Q_{\text {abs }}}{A_{c} \cdot B_{n}} \\
& =\eta_{\text {geo }} \cdot \eta_{\text {shadow }} \cdot \eta_{\text {endloss }} \cdot \eta_{\text {track }} \cdot \rho_{m} \cdot \eta_{\text {gen }} \cdot K \cdot \mathrm{Cl} .
\end{aligned}
$$

The values of $\eta_{\text {geo }}, \rho_{m}$, and $\eta_{\text {track }}$ can be measured by the instrument [24]. The incidence angle modifier (IAM) corrects for some additional reflection and absorption losses. The incidence angle modifier is given as an empirical fit to experimental data for a given collector type. The Incident Angle Modifier $K$ is calculated according to $[25,26]$

$$
K=\cos \left(\theta_{i}\right)+0.00084 \theta_{i}-0.00005369 \theta_{i}^{2} .
$$

Figure 3 is a schematic diagram of the end loss of parabolic trough solar concentrator, $S$ is the sun vector, $N$ is the vector perpendicular to the aperture area, and $\theta_{i}$ is the angle of solar incidence. When the sun light through the reflective mirror gathered to the receiver, a part of the length of the receiver cannot accept the radiation energy by the reflective mirror because the parabolic trough solar collector is generally horizontal layout and single axis tracking the sun. The end losses are the function of the focal length of the collector, the length of the collector, and the incident angle. The factor for the end loss is $[22,25]$

$$
\eta_{\text {endloss }}=1-\frac{L_{f} \tan \left(\theta_{i}\right)}{L_{\mathrm{PTC}}},
$$

where $L_{f}$ is the focal length of PTCs; $L_{\mathrm{PTC}}$ is the length of PTCs.

The factor $\eta_{\text {shadow }}$ for the calculation of the shadow from row to row at low solar altitude is [27], as shown in Figure 4. Consider

$$
\eta_{\text {shadow }}=|\cos \rho| \frac{L_{\text {space }}}{w},
$$

where $L_{\text {space }}$ is center distance of two parabolic trough concentrators; $w$ is aperture width; $\rho$ is the sun-tracking angle. Equation (7) is bounded with a minimum value of 0 (rows are fully shaded) and a maximum value of 1 (rows are not shaded).

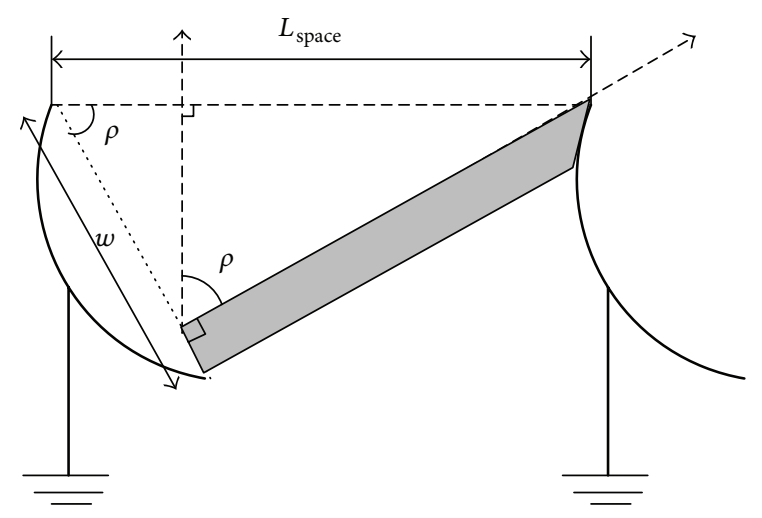

FIgUre 4: Two adjacent PTCs shadowing.

2.3. Solar Incidence Angle. Only the insolation that is directly normal to the collector surface can be focused and thus be available to warm the absorber tubes. The angle of incidence $\theta_{i}$ represents the angle between the beam radiation on a surface and the plane normal to that surface. The angle of incidence will vary over the course of the day (as well as throughout the year) and will heavily influence the performance of the collectors [28].

Once the declination angle, hour angle, and zenith angle are known, the angle of incidence on the collectors and the sun-tracking angle can be calculated. The incidence angle for a plane rotated about a horizontal north-south axis with continuous east-west tracking to minimize the angle of incidence and the sun-tracking angle is given by $[29,30]$

$$
\begin{aligned}
\theta_{i} & =\arccos \sqrt{\cos ^{2}(\alpha)+\cos ^{2}\left(\delta_{s}\right) \sin ^{2}(\omega)}, \\
\rho & =\tan ^{-1}\left[\frac{\cos \left(\alpha_{s}\right)}{\tan \alpha}\right]
\end{aligned}
$$

where $\omega$ is the hour angle; $\delta_{s}$ is the declination of the sun; $\alpha$ is the solar altitude angle; $\alpha_{s}$ is the solar azimuth angle.

2.4. Calculation for Position of the Sun. The position of the sun depends on the hour angle; the hour angle is negative when the sun is east of the local meridian (in the morning), positive when the sun is west of the local meridian (afternoon), and zero when the sun is in line with the local meridian (noon). The calculation formula of hour angle is [27]

$$
\omega=\left(t_{\mathrm{sol}}-12\right) \cdot 15^{\circ},
$$

where $t_{\text {sol }}$ is the solar time angle.

There is an important distinction between standard time and solar time. In solar time, the sun aligns with the local meridian $(\omega=0)$ at exactly 12:00 or "solar noon." However, standard time is not based on the local meridian but on a standard meridian for the local time zone. The standard time must be adjusted to reflect the current time of day in solar 
time. The relationship between solar time and standard time, in hours, is

$$
t_{\mathrm{sol}}=t_{\mathrm{st}}-t_{\mathrm{ad}}+\frac{L_{\mathrm{st}}-L_{\mathrm{loc}}}{15}+\frac{\mathrm{EOT}}{60},
$$

where $t_{\text {st }}$ is on a standard meridian for the local time zone; $t_{\mathrm{ad}}$ is daylight saving time adjustment; $L_{\text {st }}$ is standard meridian for the local time zone; $L_{\text {loc }}$ is the local meridian of the collector site; EOT is an equation of time that determines the deviation in local time from solar time as a function of the day of the year; the calculation process of equation of time is as follows [29]:

$$
\begin{aligned}
\mathrm{EOT}= & 0.00096+0.0171856 \cos B-0.2951084 \sin B \\
& -0.134458 \cos (2 B)-0.376188 \sin (2 B),
\end{aligned}
$$

where

$$
B=0.986(d-1)
$$

where $d$ is the day number of the year ( 1 for January 1, 365 for December 31).

The declination angle is [30]

$$
\delta_{s}=23.45 \sin (280.11+0.984 d) .
$$

When the declination angle and hour angle were calculated, the solar altitude and solar azimuth which are used to describe the sun position can be computed. The solar azimuth $\left(\alpha_{s}\right)$ and the solar altitude $(\alpha)$ angles are calculated [31]:

$$
\begin{aligned}
\alpha & =\arcsin \left[\sin \delta_{s} \sin \phi+\cos \phi \cos \delta_{s} \cos \omega\right], \\
\alpha_{s} & =\operatorname{sign}(\omega)\left|\arccos \left[\frac{\cos (90-\alpha) \sin \phi-\sin \delta_{s}}{\sin (90-\alpha) \cos \phi}\right]\right|,
\end{aligned}
$$

where $\phi$ is the latitude.

2.5. Calculation Flowchart. The flowchart of the method for the end losses factor, shadowing factor, cosine effect, and optical efficiency of the PTC system is shown in the block diagram in Figure 5. From the flowchart it can be seen that the solar altitude is calculated according time, latitude angle, and day number inputs; then solar azimuth and angle of incidence are calculated. The cosine effect, incidence angle modifier, and sun-tracking angle are calculated by using the angle of incidence. The factor for the end loss is calculated by using the angle of incidence, focus length, and length of PTC. The total efficiency can be obtained by using the results of the above calculation and the tracking error, mirror reflectance, and general error inputs.

2.6. Model Validation. The model can be validated by comparing Patnode's test results in SEGS VI concentrating solar power station (2005) [28], based on some typical test conditions shown in Table 1 [7]. The station is located at $35^{\circ} 0^{\prime} 51.0^{\prime \prime}$ north, $117^{\circ} 33^{\prime} 32.0^{\prime \prime}$ west [32]. To calculate the optical efficiency of the parabolic trough concentrator using the model, the power absorbed by the receiver of the PTC

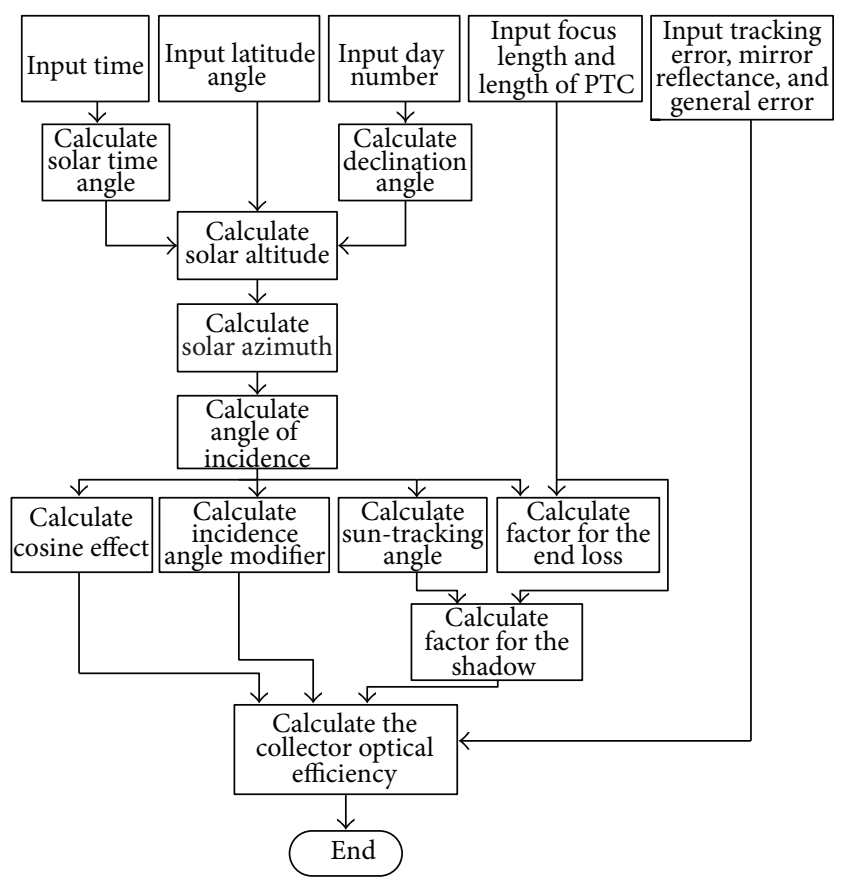

FIGURE 5: Flowchart of calculating the end losses factor, shadowing factor, cosine effect, and optical efficiency.

TABLE 1: Main parameters of SEGS VI’s PTC [7].

\begin{tabular}{lc}
\hline Parameters & Data \\
\hline Focus length & $1.4 \mathrm{~m}$ \\
Aperture width & $5 \mathrm{~m}$ \\
Length of collector & $47.1 \mathrm{~m}$ \\
Absorber tube diameter & $70 \mathrm{~mm}$ \\
Absorptance & 0.97 \\
Aperture area & $235.5 \mathrm{~m}^{2}$ \\
Mirror reflectance & 0.94 \\
\hline
\end{tabular}

is calculated according to formula (4); calculation results are compared with the test data. The comparisons between the simulations and experiments are shown in Figure 6. As can be seen from Figure 6 , the numerical results on the heat rate error are between 4 and $20 \mathrm{~W} / \mathrm{m}^{2}$, with a relative error range of $1 \%$ to the estimated values of $5 \%$. Calculation results are compared with that of experiments; it is found that calculation results are lower than experiment data; the main reason is that the tracking error is assumed to be a constant in this paper, and many other parameters like the thermic fluid and materials of the collector are not considered and the error is affected. Overall, as can be seen from Figure 6 the mathematical model of this paper can correctly reflect the operating characteristics of PTCs.

\section{Results and Discussion in Typical Areas of China}

A typical parabolic trough solar collector with the receiver of the radius of envelope 0.12 meters was calculated. The 
TABLE 2: Parameters of the parabolic trough solar collector.

\begin{tabular}{lc}
\hline Parameters & Data \\
\hline Focus length & $1.8 \mathrm{~m}$ \\
Aperture width & $5.75 \mathrm{~m}$ \\
Length of collector & $100 \mathrm{~m}$ \\
Radius of envelope of receiver & $0.12 \mathrm{~m}$ \\
Row space & $15 \mathrm{~m}$ \\
Geometry effects & 0.98 \\
Cleanliness factor & 0.95 \\
Mirror reflectance & 0.935 \\
Tracking error & 0.994 \\
\hline
\end{tabular}

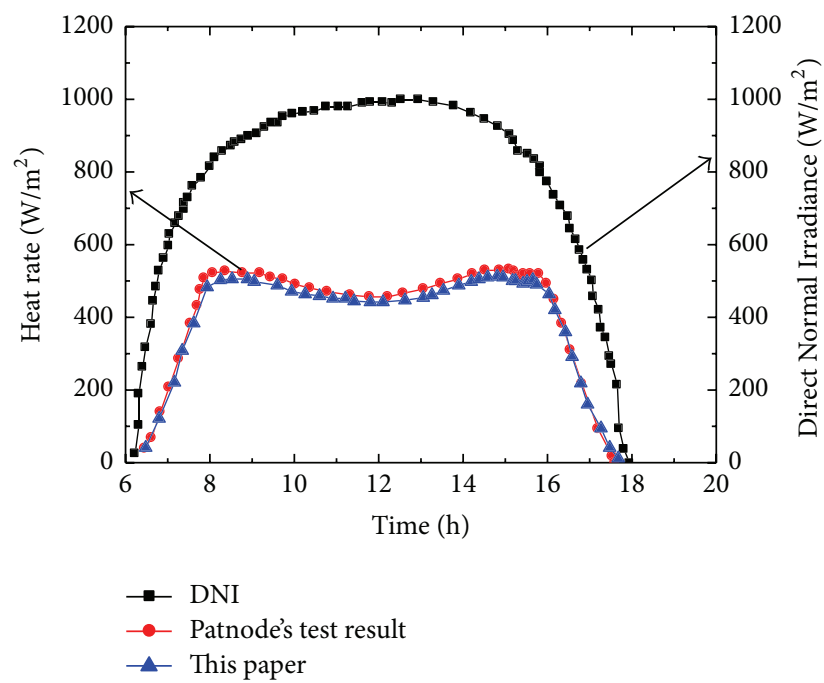

FIgure 6: Comparisons between the mode and Patnode's test results for validation.

parameters for the collector were shown at Table 2, prototype as shown in Figure 7.

The parabolic trough solar collector with these parameters has been designed by Jiangsu Provincial Key Laboratory of Solar Energy Science and Technology, as shown in Figure 7.

The three typical regions of China were chosen as the computing sites which are Lhasa Tibet, Delingha, Qinghai, and Dunhuang, Gansu, geographic coordinates as shown in Table 3.

The optical efficiency, cosine factor, solar shading factor, end loss factor, and annual average values at any time in these three areas were compared with simulation studies and analysis. For the convenience, the first days per month in a year were chosen for performance simulation. Figure 8 shows the changing trend of the collector optical efficiency. The optical efficiency of PTC changes from 0.4 to 0.8 in a whole year. The efficiency first decreased and then increased with the turning point of the change at noon. The highest operating collector optical efficiency is in June, and the efficiency is relatively higher from April to August. The lowest operating collector optical efficiency is in December, and the efficiency is relatively lower and the difference of efficiency in these
TABLE 3: Computing sites.

\begin{tabular}{lc}
\hline Regions & Geographic coordinates \\
\hline Delingha & N: $37.37^{\circ}$, E: $97.37^{\circ}$ \\
Dunhuang & N: $40.15^{\circ}$, E: $94.68^{\circ}$ \\
Lhasa & N: $29.67^{\circ}$, E: $91.13^{\circ}$ \\
\hline
\end{tabular}

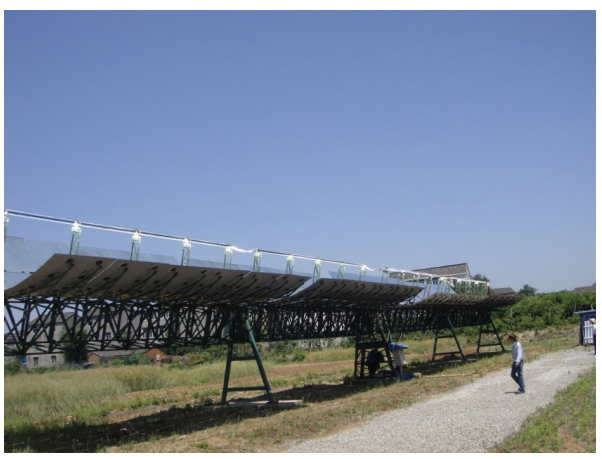

FIGURE 7: A prototype of parabolic trough solar collector.

three areas is also greater in January, October, and November. From Figure 8 it is evident that the optical efficiency of PTCs operated in Lhasa is higher than in Delingha, and the optical efficiency of PTCs operated in Delingha is higher than in Dunhuang. As can be seen from formula (4), the difference of operating optical efficiency in these three regions is mainly determined by collector cosine effect, end loss factor, and solar shading factor. The angle of incidence of the sun is the angle between the rays of the sun and the normal. The solar incidence angle changes with the angle of the solar zenith angle and the azimuth angle.

From Figure 9, we can see that the changing trend of the collector cosine effect is basically the same as the trend of the optical efficiency. From October to March, the value of the cosine effect is larger, ranging from 0.7 to 0.98 , while it is smaller in October, November, December, and January. The cosine effect in Lhasa is larger than in Delingha, and in Delingha it is larger than Dunhuang.

Figure 10 shows the changing trend of collector end loss factor. End losses occur at the ends of the PTCs, where, for a nonzero incidence angle, some length of the absorber tube is not illuminated by solar radiation reflected from the mirrors. The collector end loss factor is mainly affected by tangent angle of incidence of the sun. As it can be seen from the figure that the end loss factor is lowest at noon every day except for June and July, the minimum value appeared at sunrise and sunset in June and July, and the value is relatively close in March, February, and November in all the three areas, which ranged from 0.985 to 1 . The end loss factors in Delingha and Delingha are basically the same; the value in Lhasa is slightly larger than the other two areas.

Figure 11 shows changing trend of shadowing effect. In this study, the two adjacent PTCs are arranged in parallel rows, with about $15 \mathrm{~m}$ of spacing within each row. PTCs track the sun toward the east at sunrise and toward the west at sunset. Due to the low solar altitude angle of the 


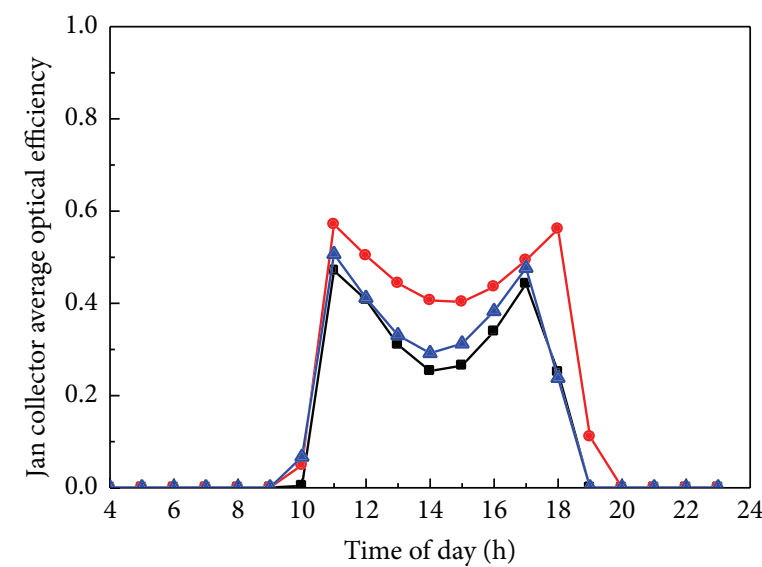

(a)

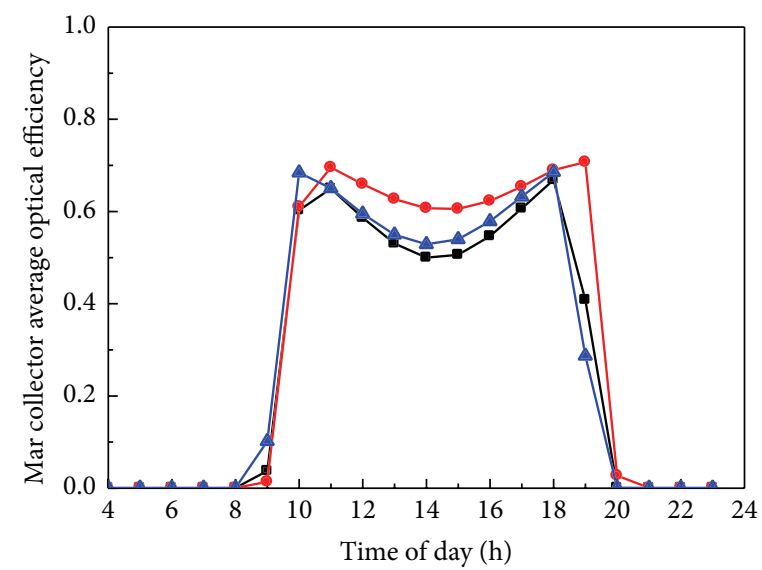

(c)

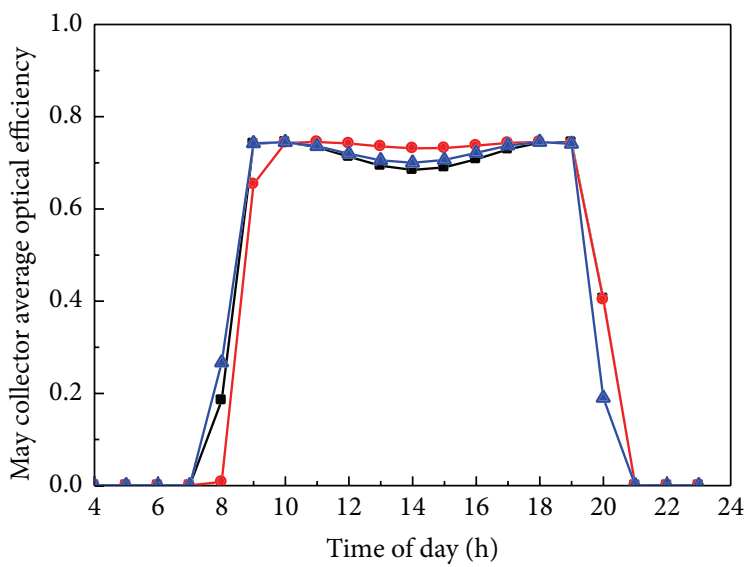

(e)

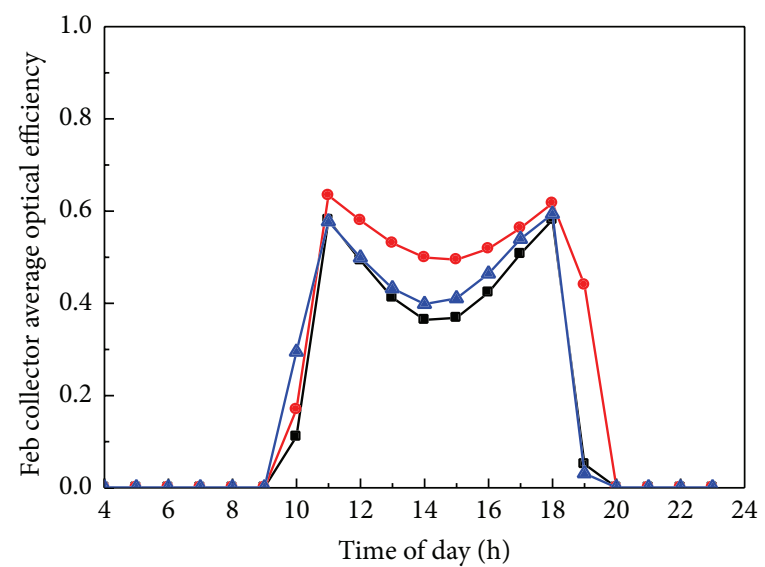

(b)

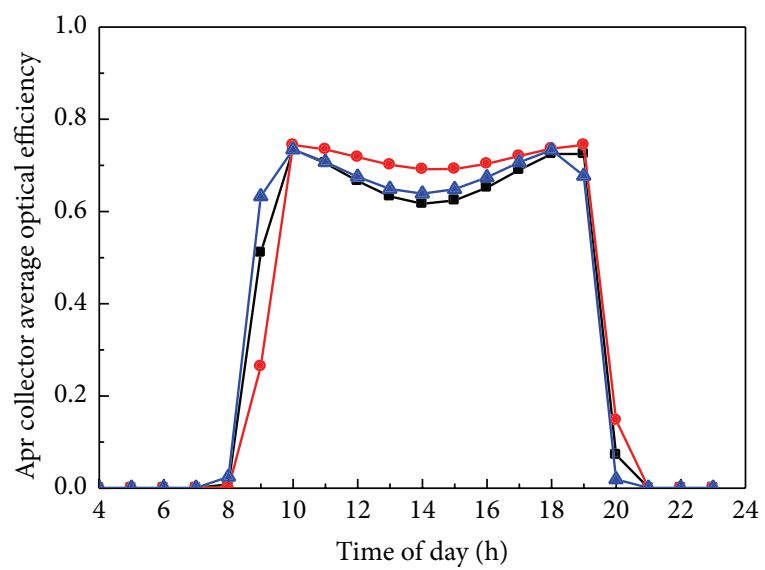

(d)

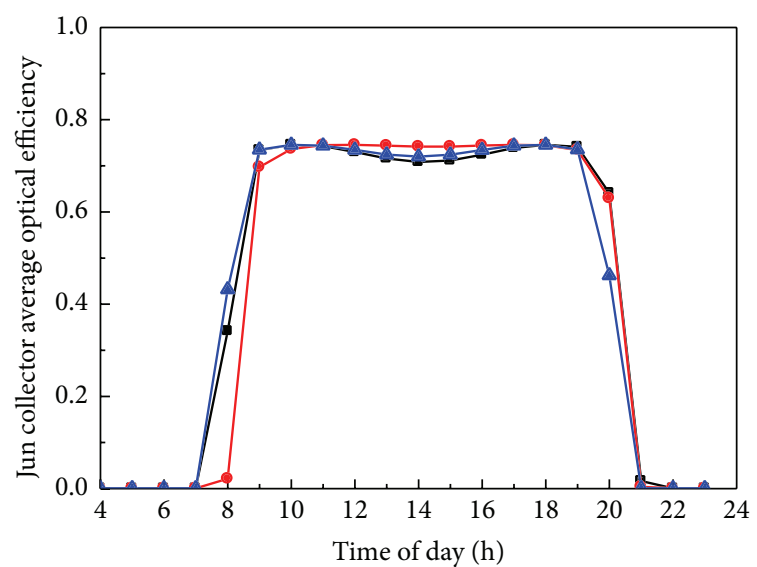

(f)

FIgURE 8: Continued. 


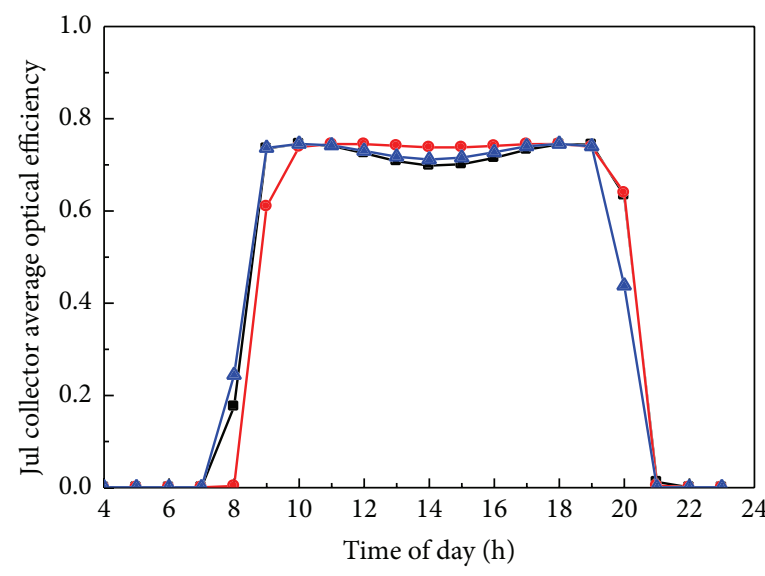

(g)

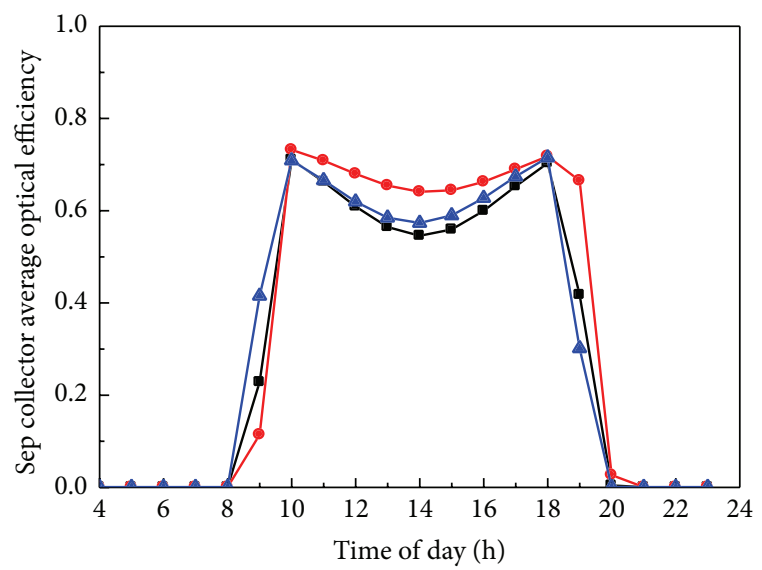

(i)

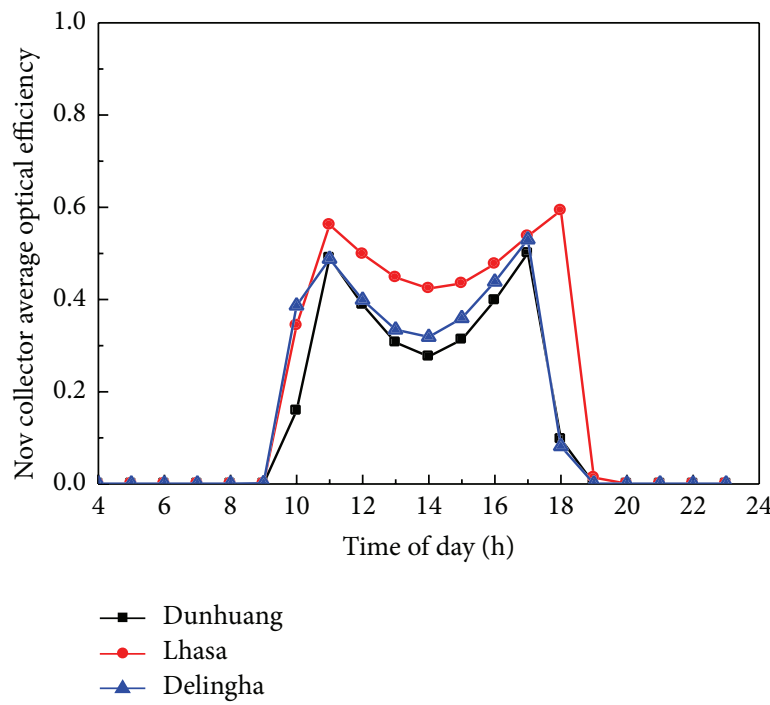

(k)

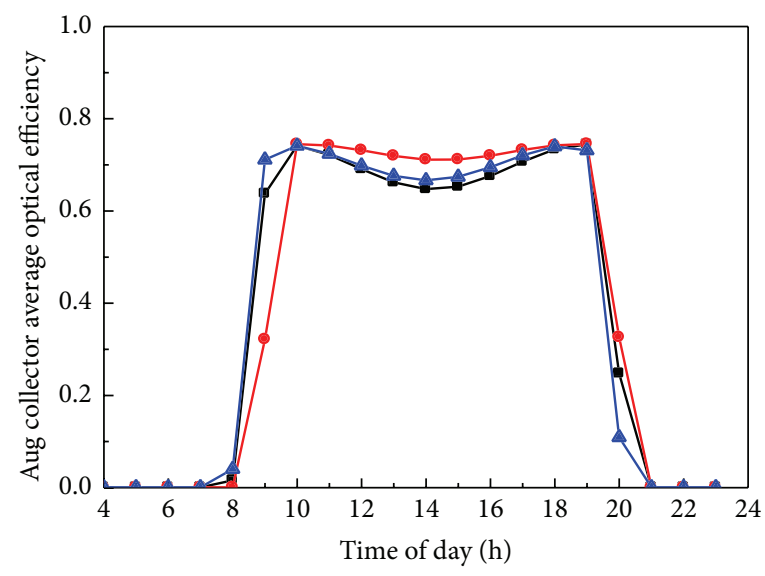

(h)

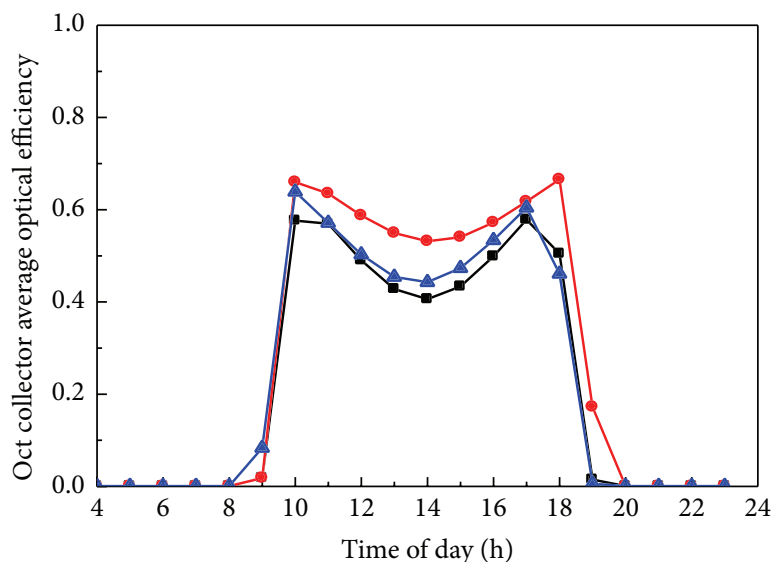

(j)

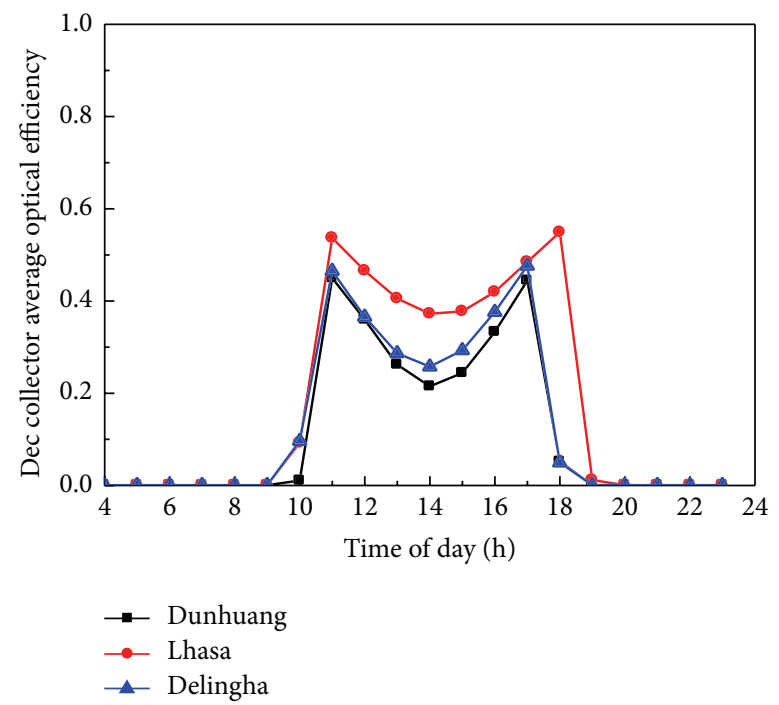

(l)

Figure 8: Collector optical efficiency.

sun in the morning, the eastern-most row of collectors will receive full sun, but this row will shade all subsequent rows to the west. As the sun rises and the collectors track the sun, this mutual row shading effect decreases, until a critical zenith angle is reached at which no row shading occurs.
Collector rows remain unshaded through the middle of the day, from late morning through early afternoon. As seen in the figure, losses are introduced by collector shading during approximately the first and last 90 minutes of operation each day. Because the collectors are single axis tracking in 


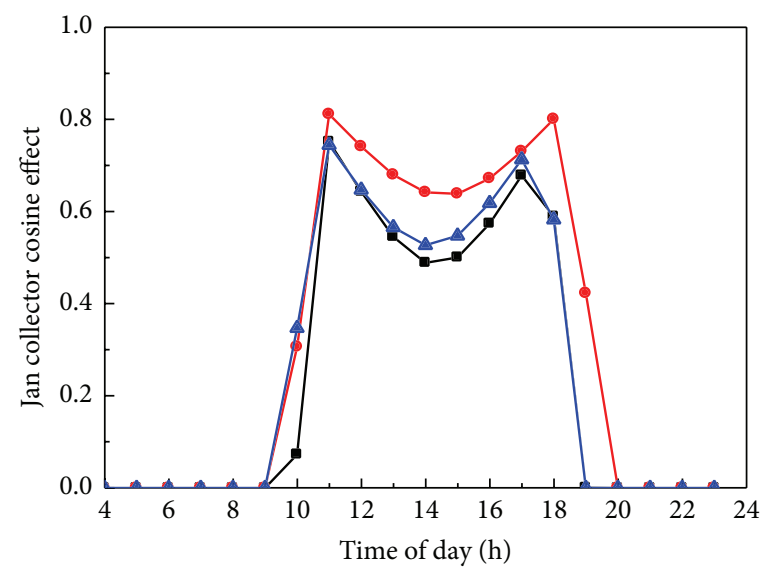

(a)

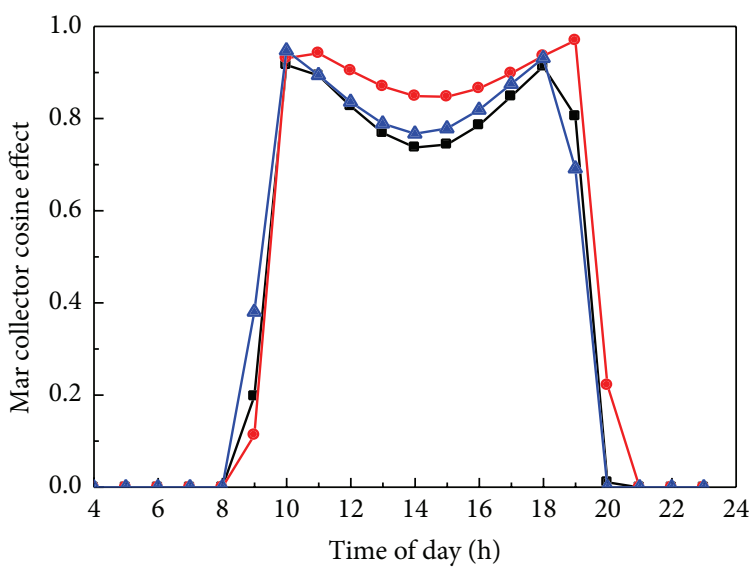

(c)

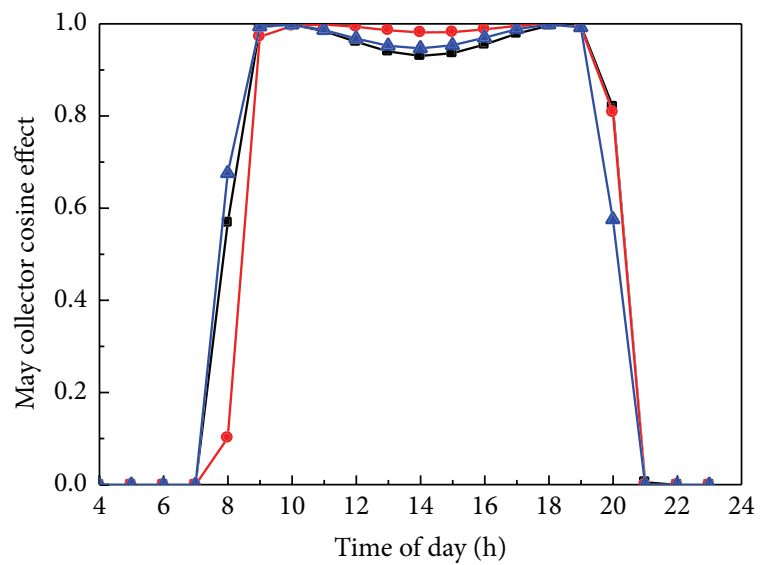

(e)

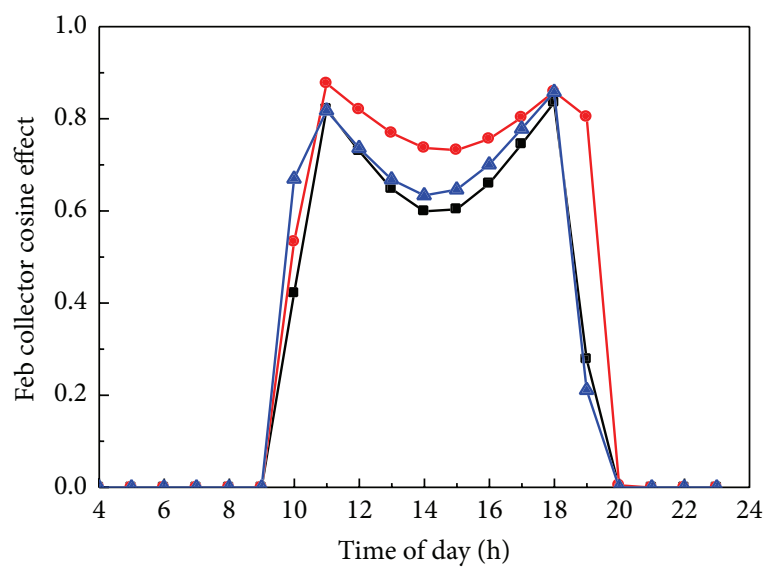

(b)

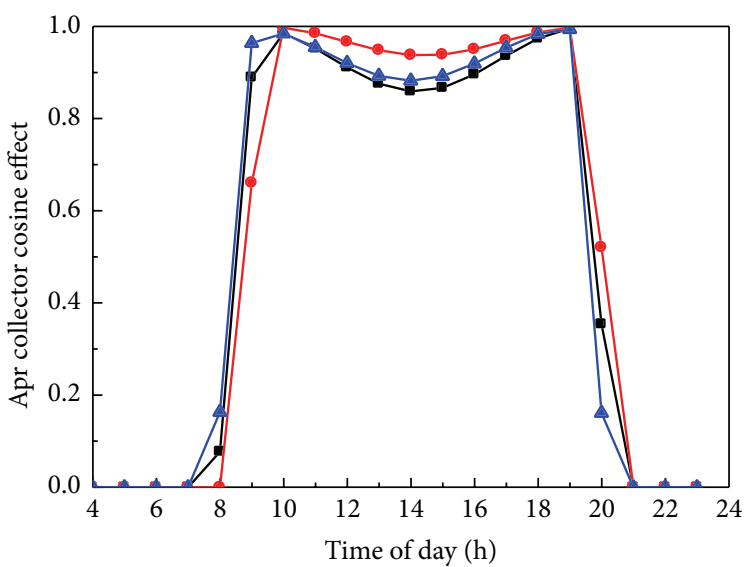

(d)

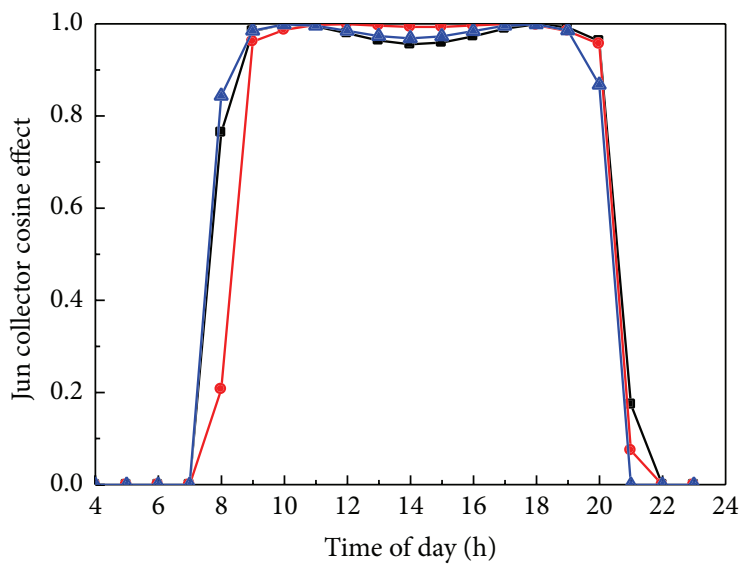

(f)

FIgURE 9: Continued. 


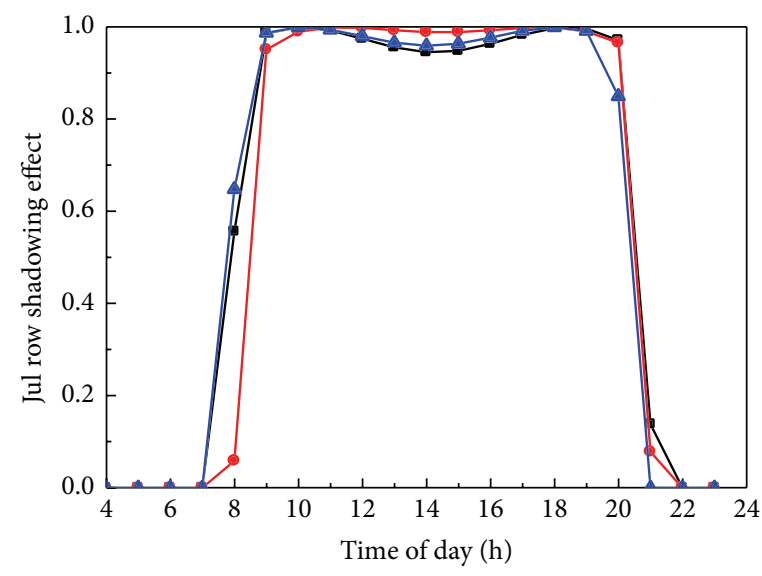

(g)

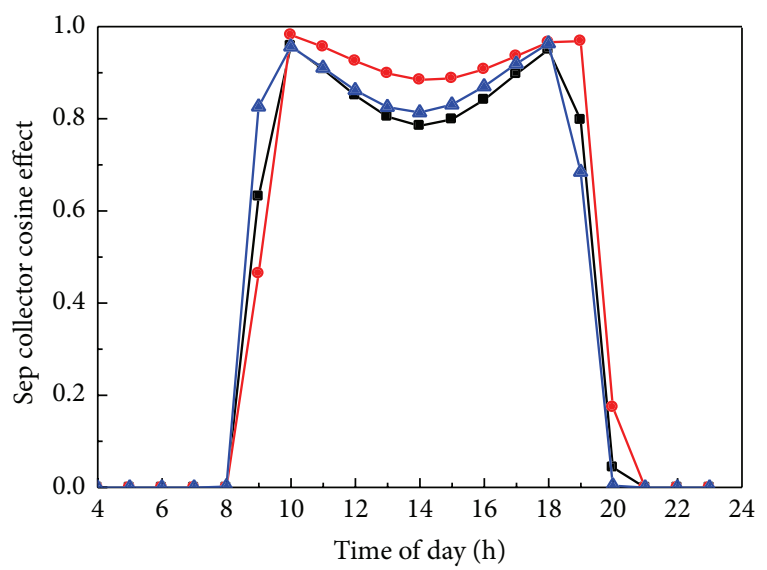

(i)

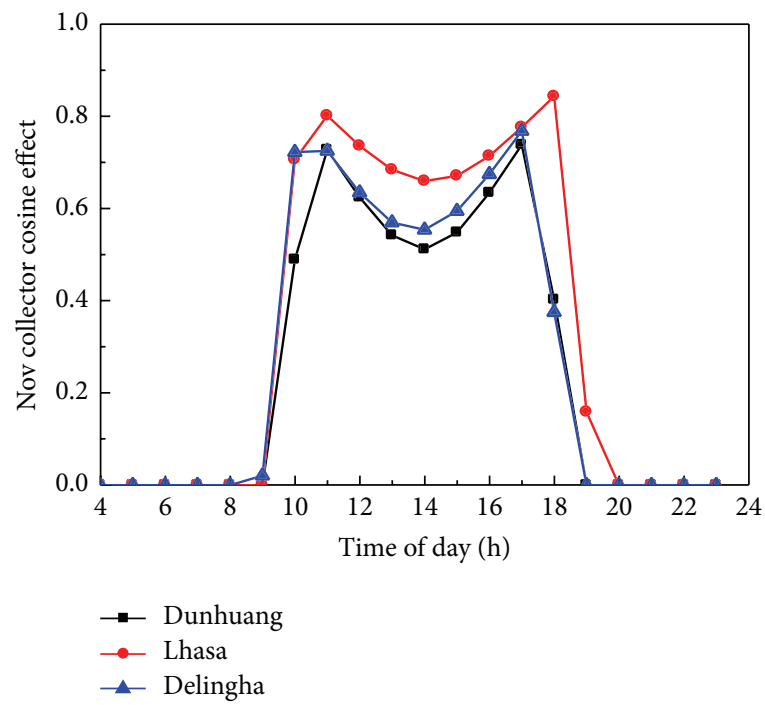

(k)

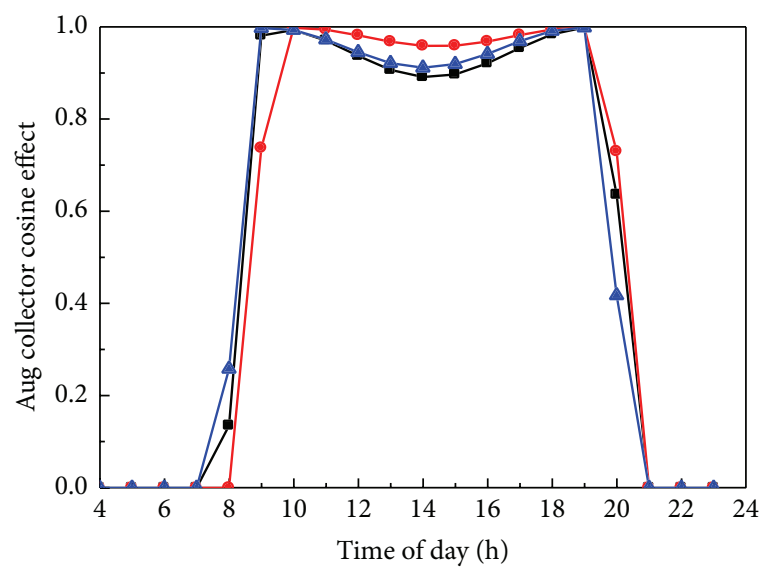

(h)

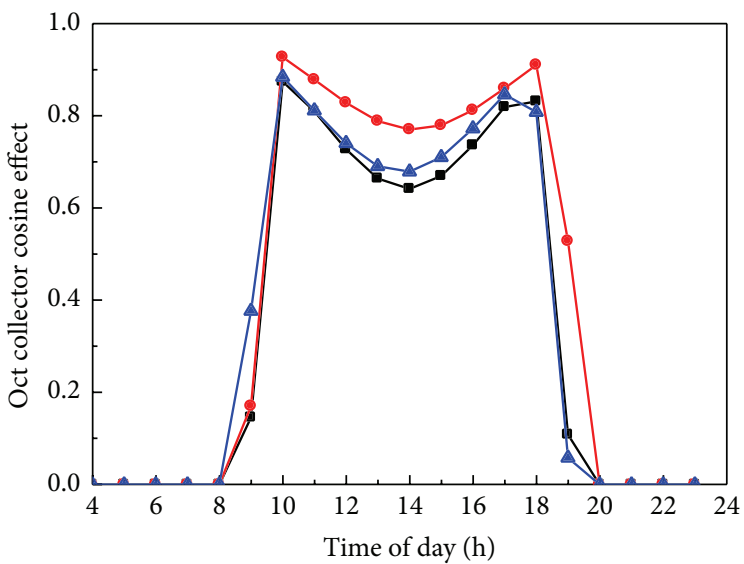

(j)

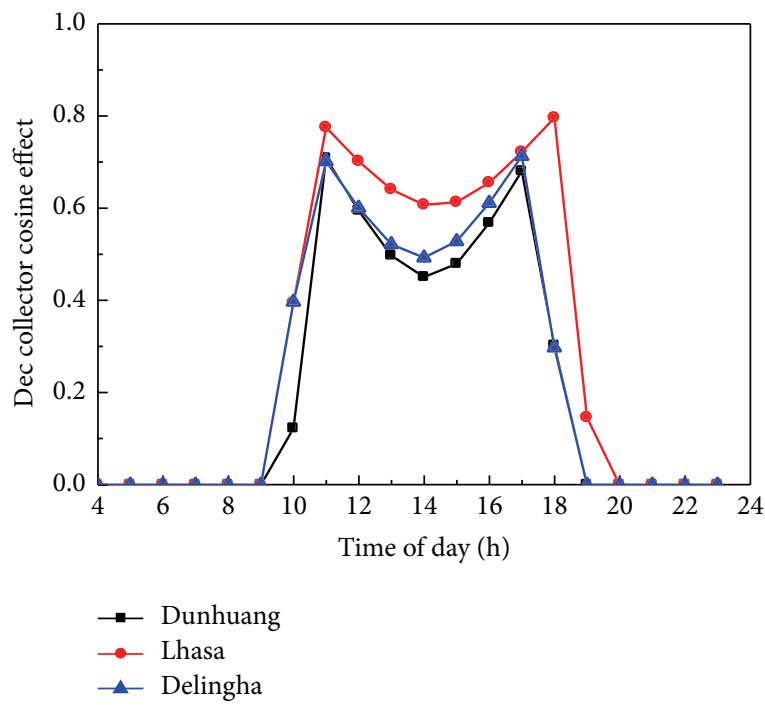

(l)

FIGURE 9: Collector cosine effect.

a north-south orientation, the length of time over which row shading occurs does not vary significantly throughout the year.

The annual values of the twelve days of the data were calculated. Figure 12 shows the annual values of cosine effect, shadowing effect, end loss effect, and optical efficiency. As it can be seen from the figure that annual optical efficiency of Lhasa is greater than Delingha, and the latter is greater than Dunhuang, the annual optical efficiency per hour during the day of the sunrise to the sunset for Lhasa is $49.6 \%$, 


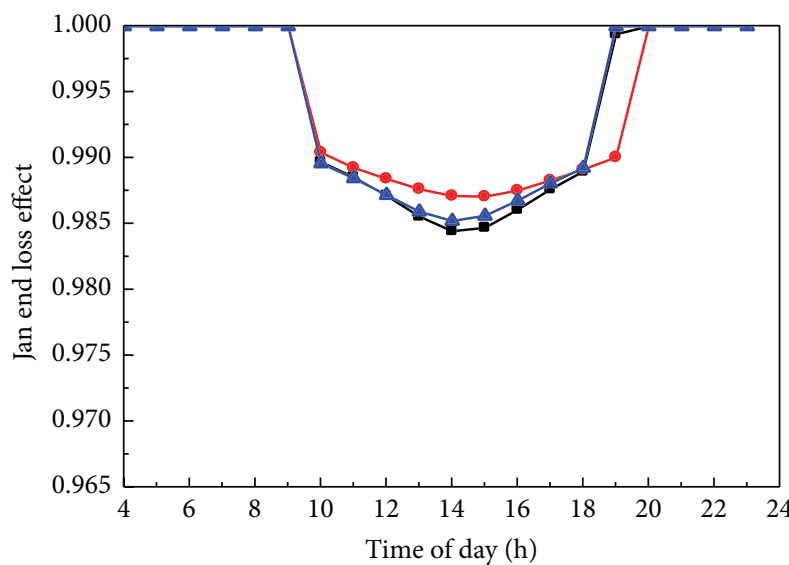

(a)

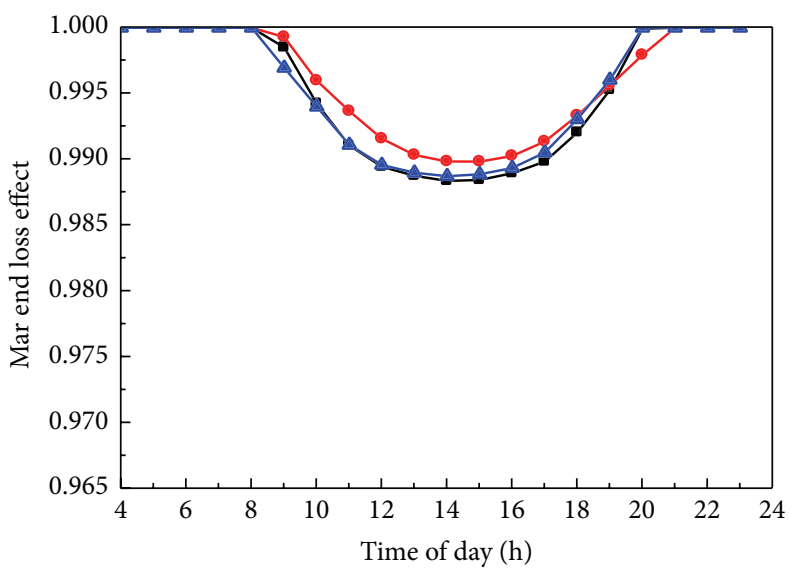

(c)

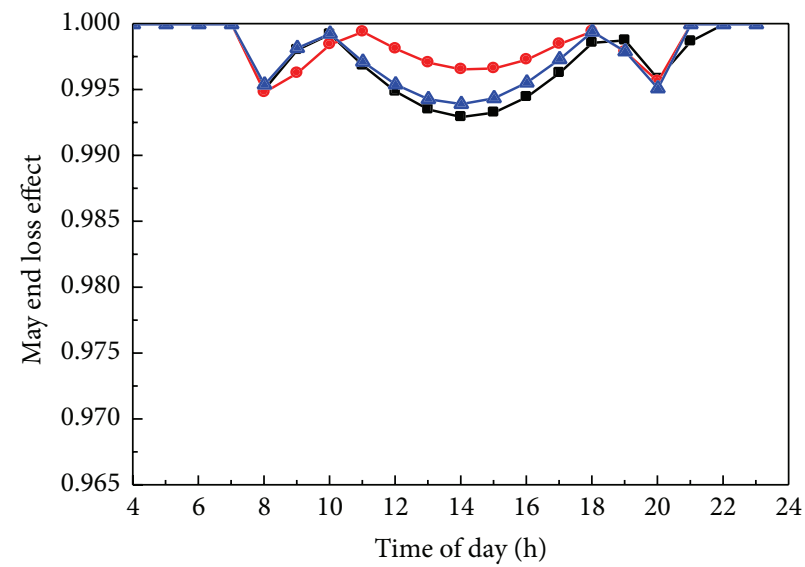

(e)

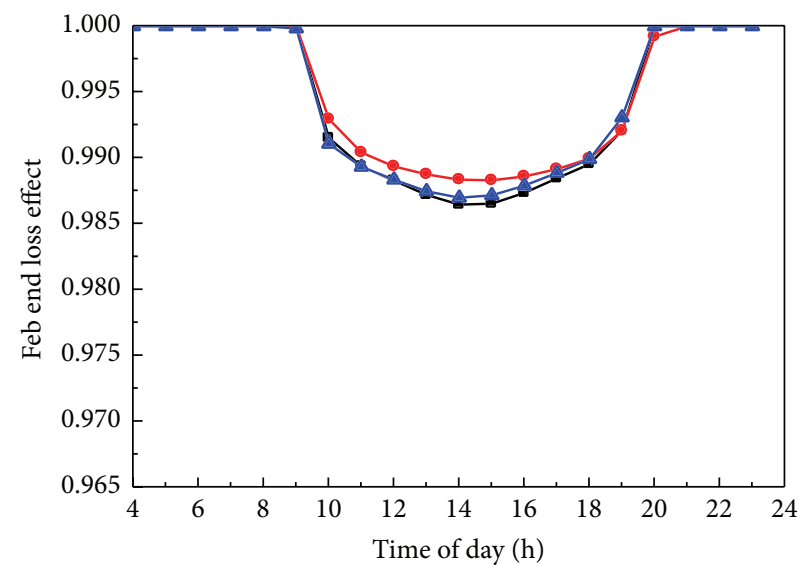

(b)

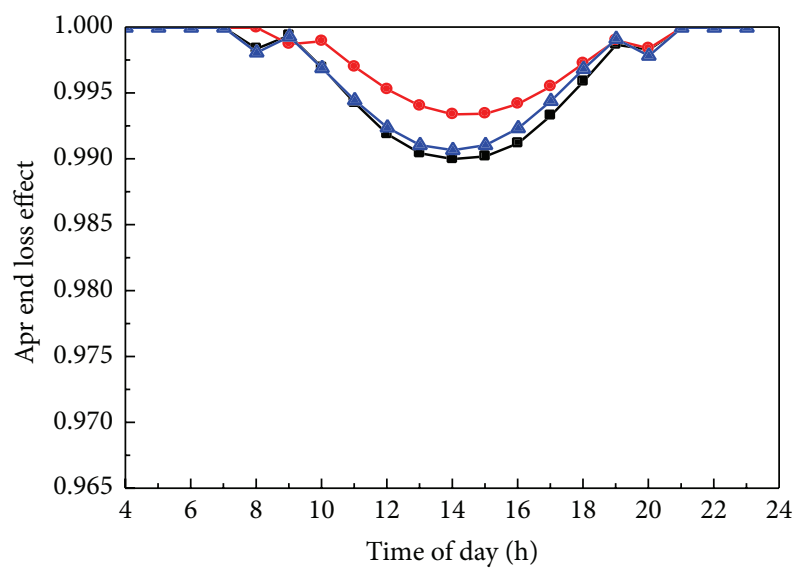

(d)

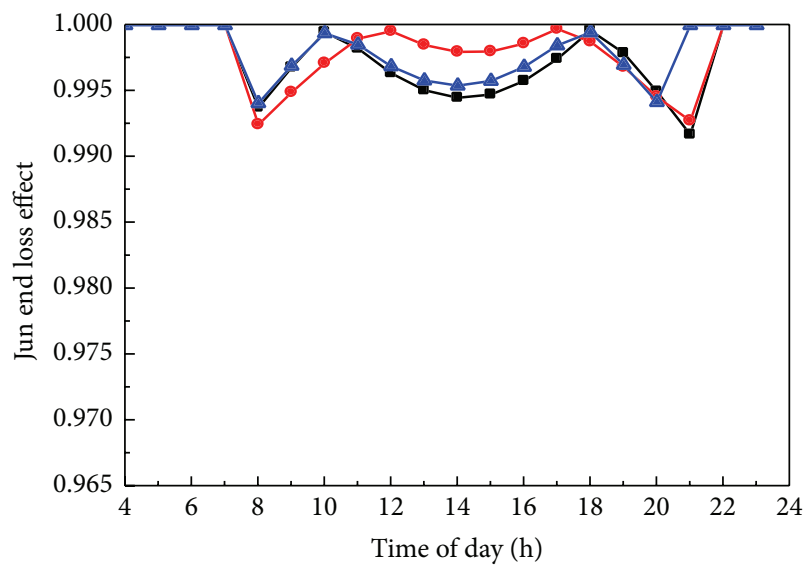

(f)

Figure 10: Continued. 


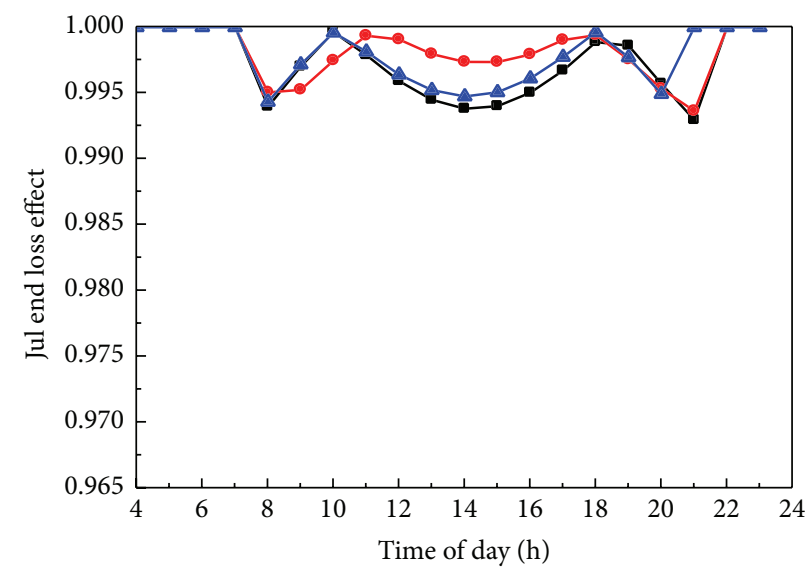

(g)

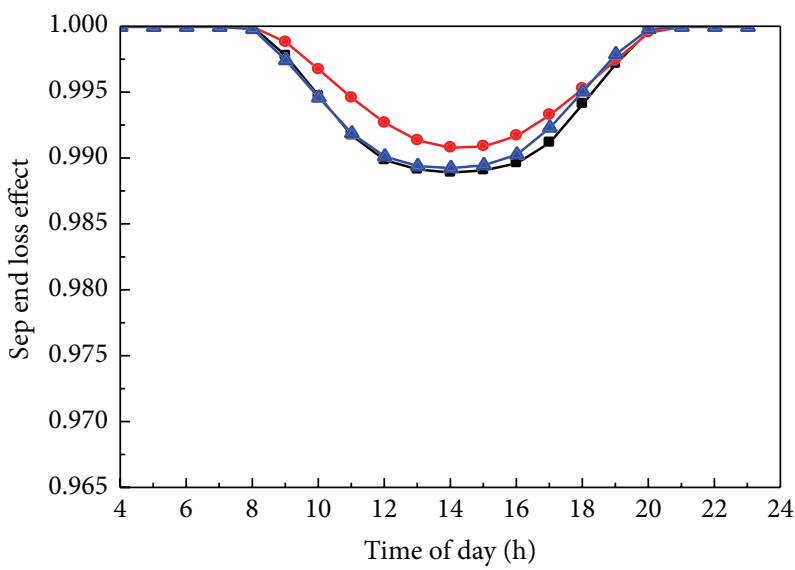

(i)

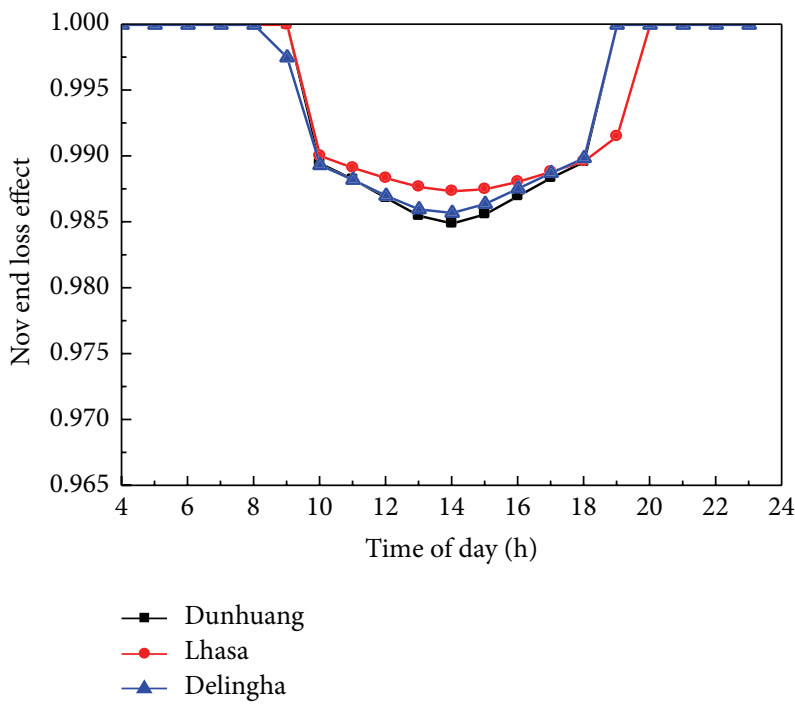

(k)

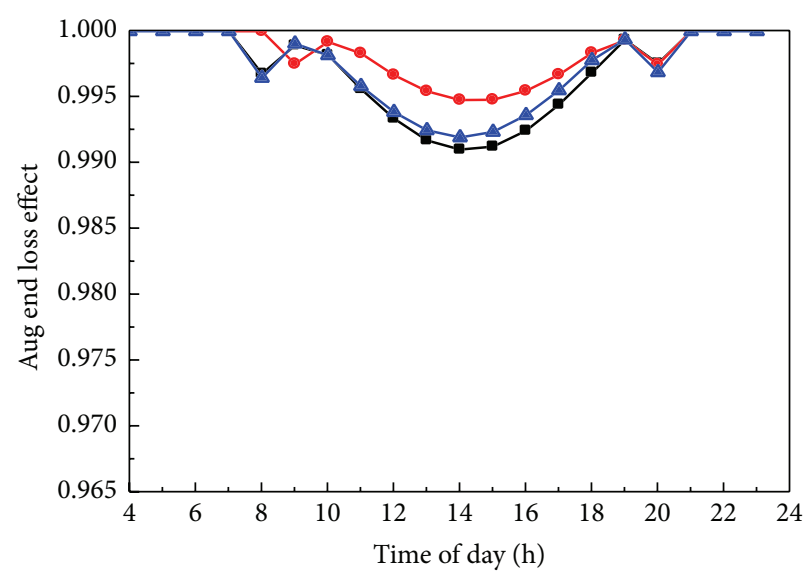

(h)

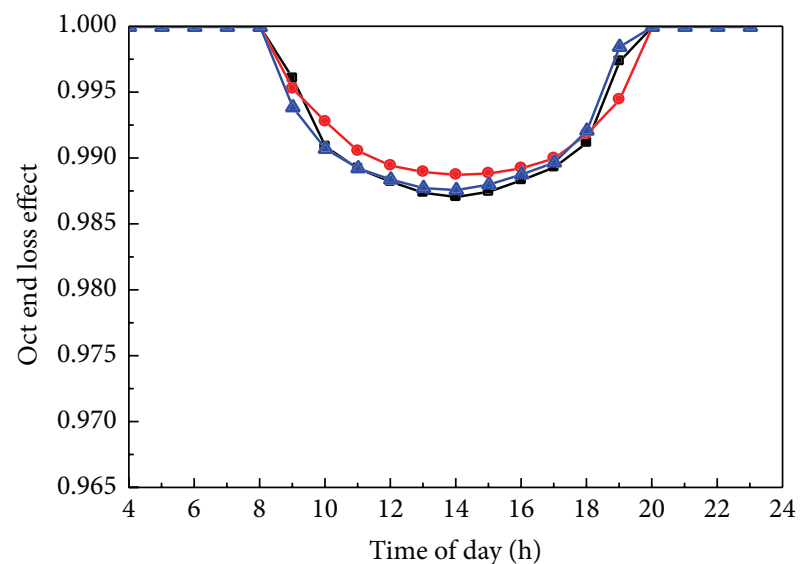

(j)

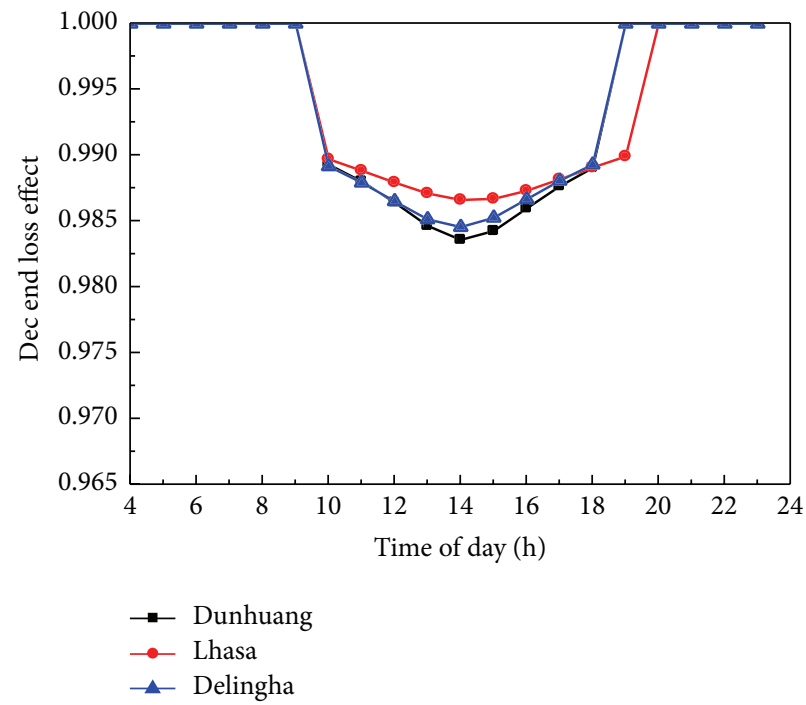

(1)

Figure 10: End loss factor.

Delingha is $46.1 \%$, and Dunhuang is $44.8 \%$. The annual values of shadowing effect and shadowing effect are very large, close to $100 \%$. The trend of annual cosine effect change is consistent with the trend of optical efficiency, which reveals that the optical efficiency is mainly influenced by the incident angle of the sun; nevertheless shadowing effect and end loss effect are weak in the effect of optical efficiency.

From the analysis above we conclude that the optical efficiency of parabolic trough solar concentrator collectors mainly by the impact of the incident angle of the sun, 


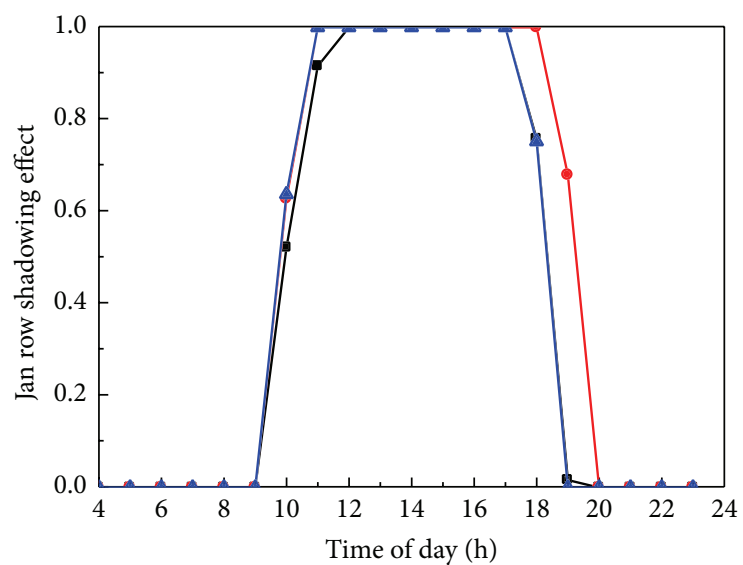

(a)

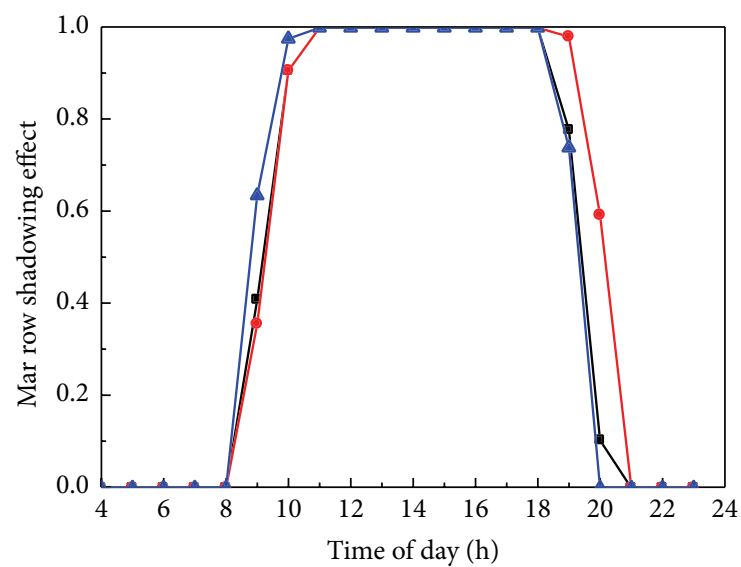

(c)

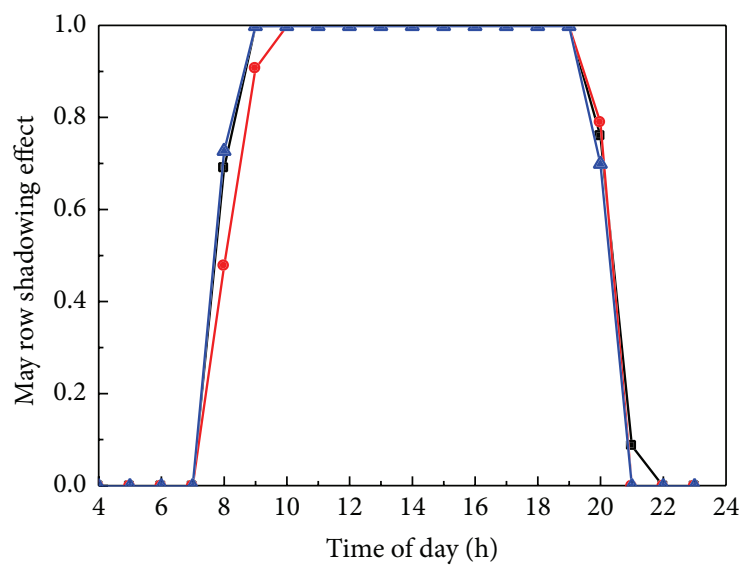

(e)

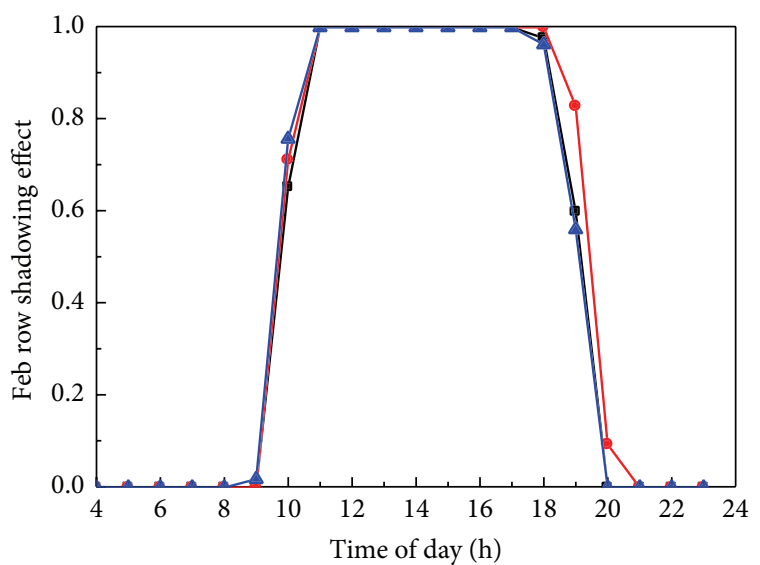

(b)

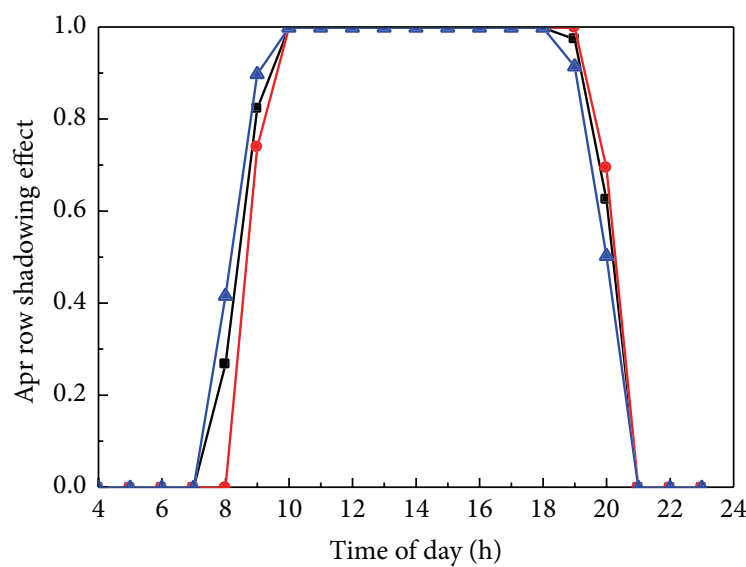

(d)

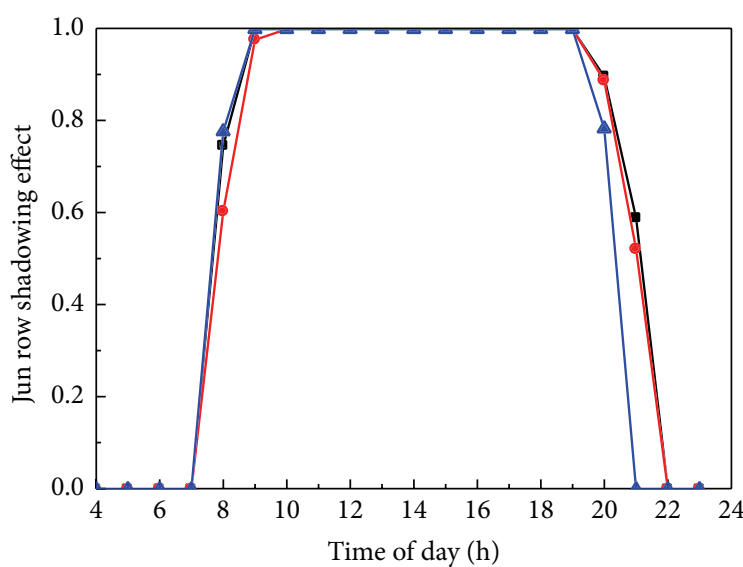

(f)

FIGURE 11: Continued. 


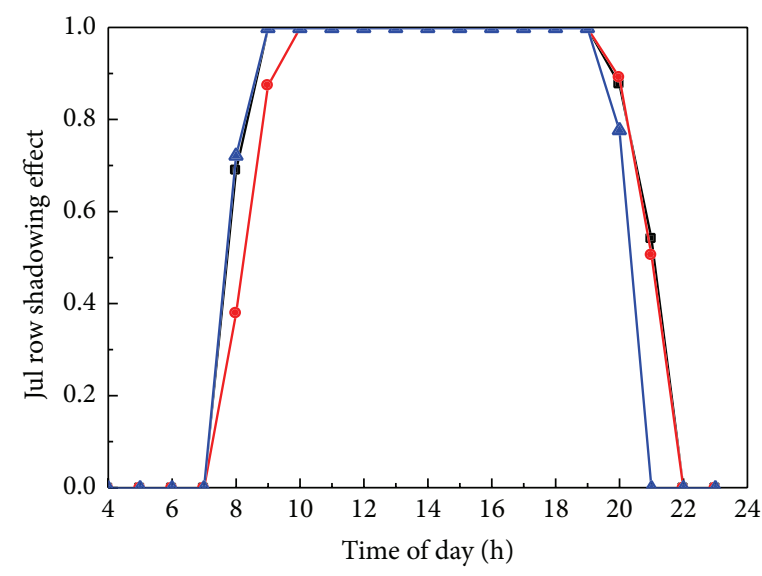

(g)

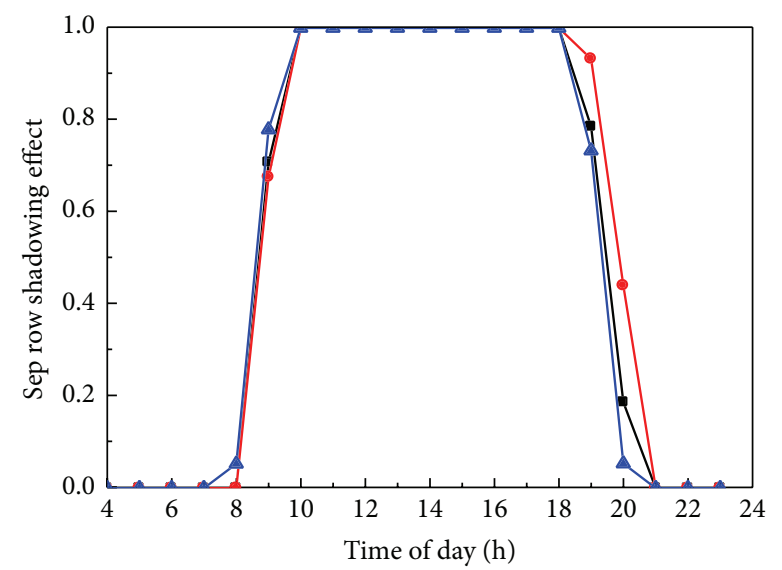

(i)

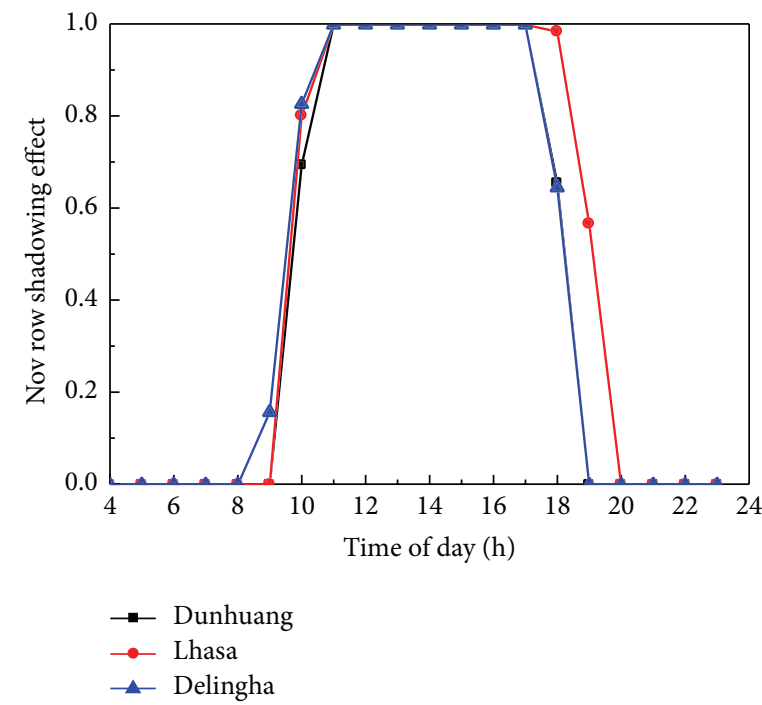

(k)

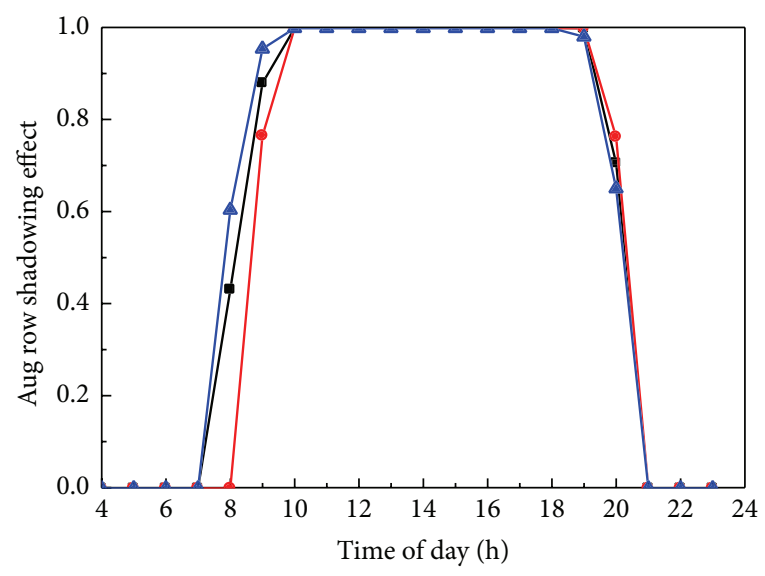

(h)

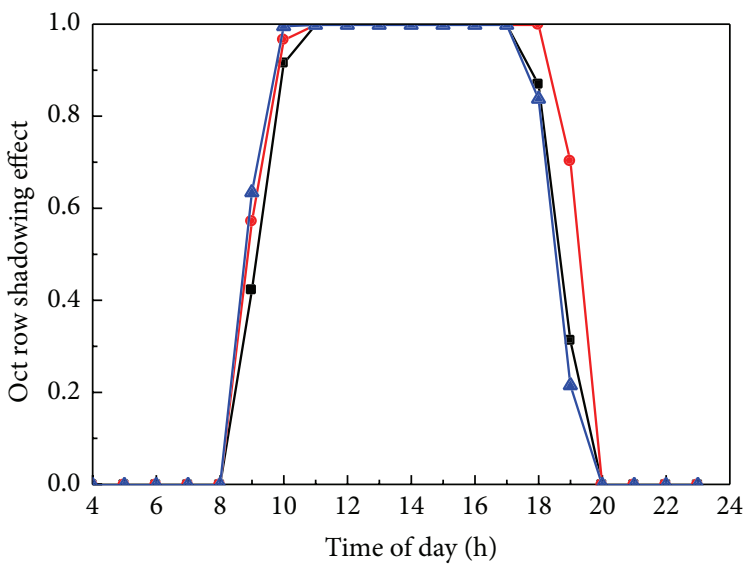

(j)

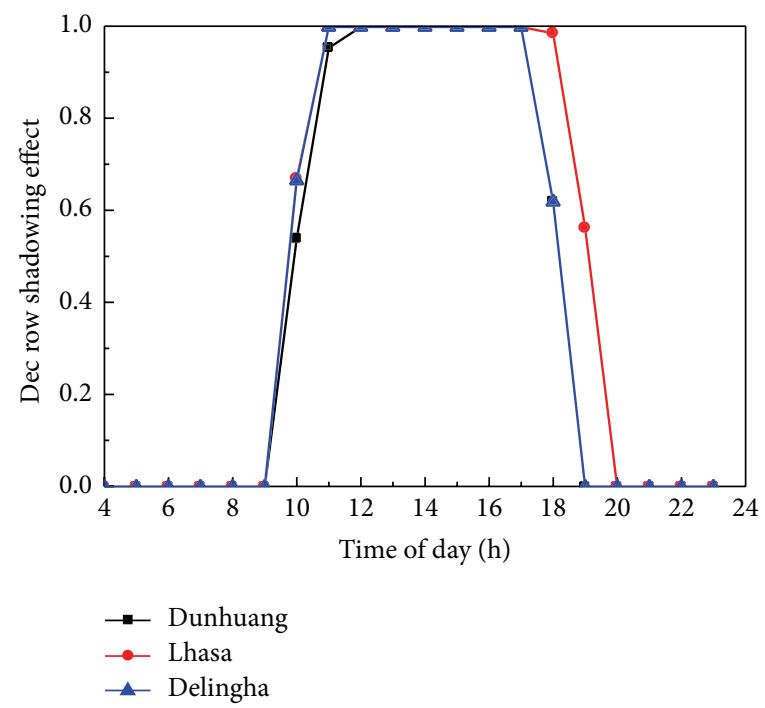

(1)

FIGURE 11: Shadowing effect.

shadowing effect, and end loss effect are almost negligible. The incident angle of the sun is mainly influenced by different geographic locations of parabolic trough solar concentrating collector. So the conclusion has important implications for the sites selection of parabolic trough solar thermal power plant.

For Parabolic Trough Power Plants location choice from Lhasa, Dunhuang, and Delingha in China, the optical 


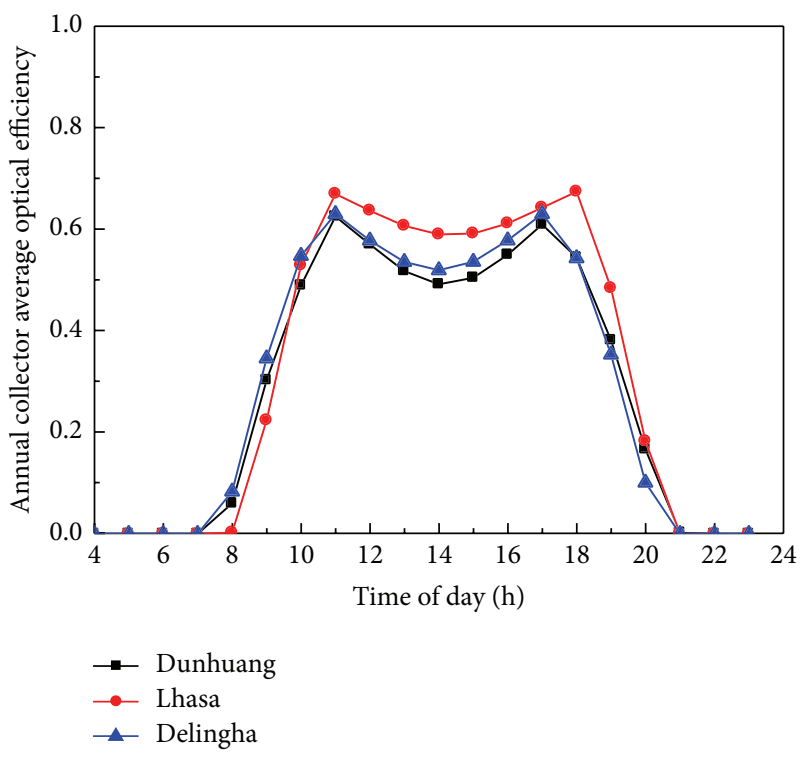

(a) Annual collector average optical efficiency

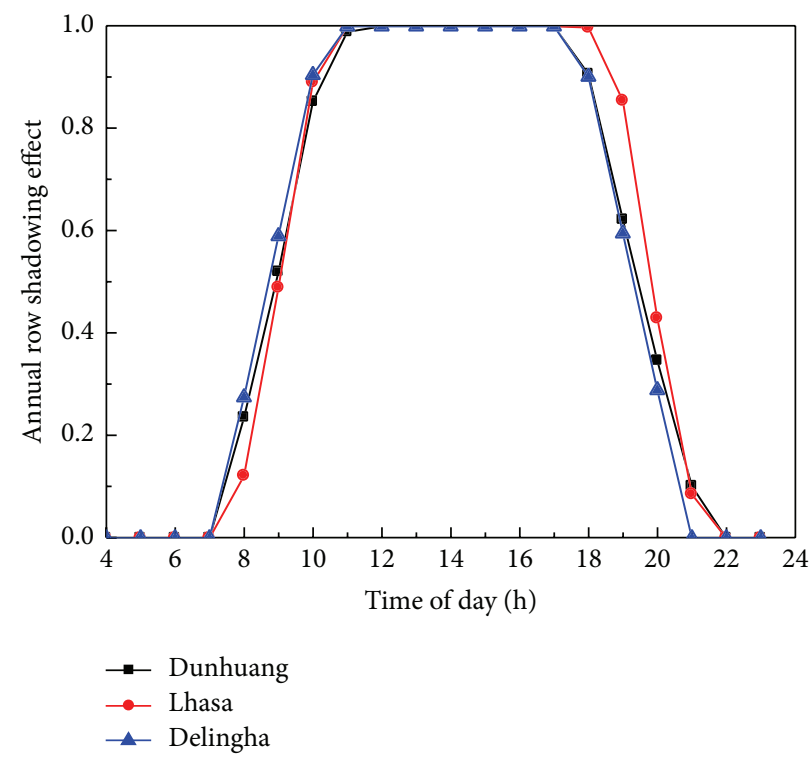

(c) Annual row shadowing

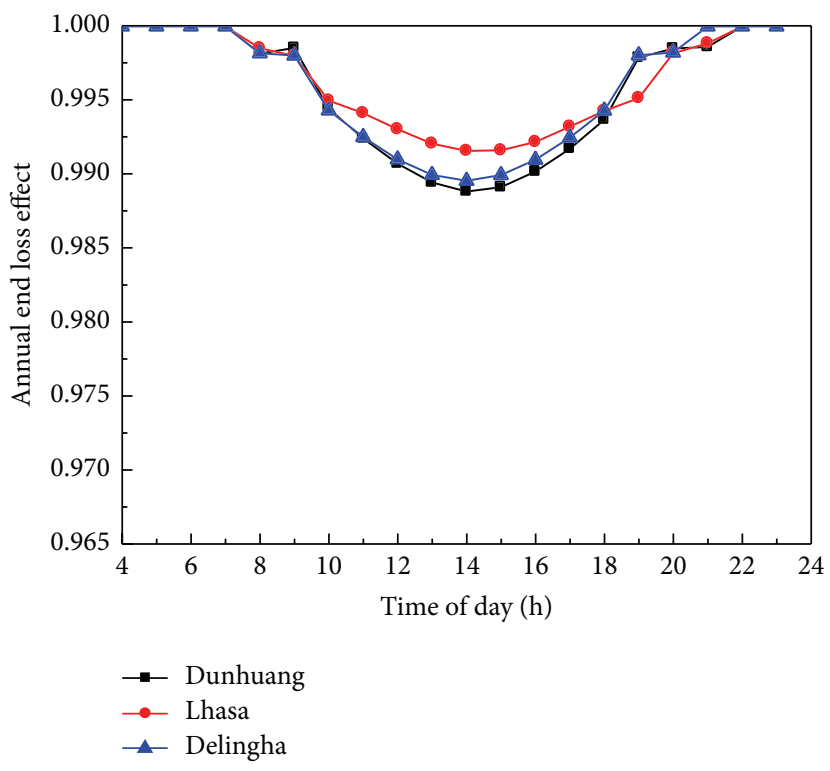

(b) Annual end loss effect

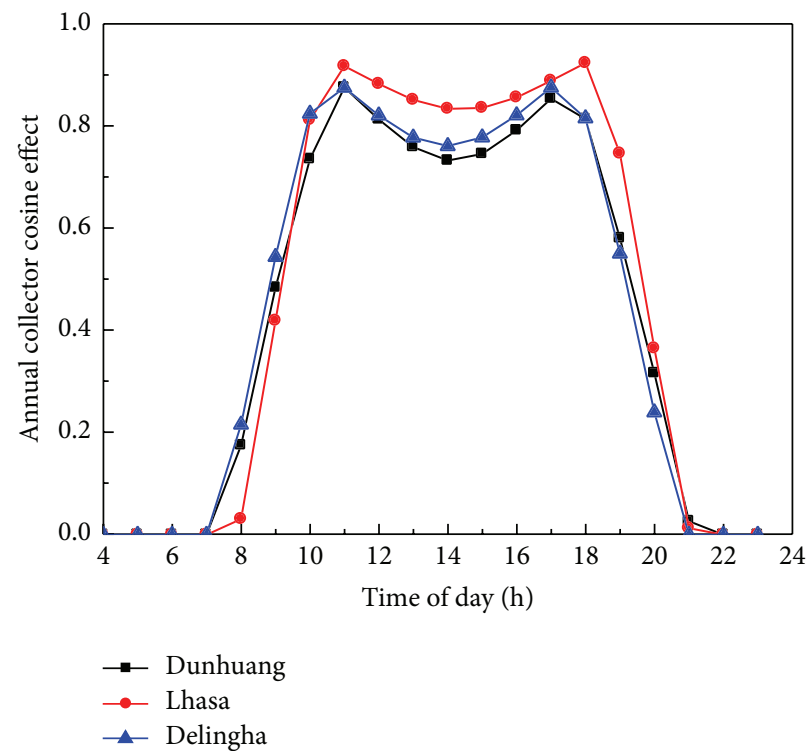

(d) Annual collector cosine effect

FIGURE 12: Annual values of cosine effect, shadowing effect, end loss effect, and optical efficiency.

efficiency of PTCs in Lhasa is higher than the other 2 regions.

\section{Conclusions}

In the paper, the optical efficiency calculation method of parabolic trough solar collector was used to analyze and study the performance of parabolic trough solar collector at Dunhuang, Delingha, and Lhasa in China. The first day of every month during a year was chosen as a time of calculation; mainly cosine effect, shadowing effect, end loss effect, and optical efficiency were calculated.

From PTCs in these three areas in China simulation results, some overall conclusions could be derived as follows.
(1) In this paper, a mathematical model of parabolic trough solar concentrator is established, which is validated by comparing the test results in SEGS VI, and performance simulation results can correctly reflect the operating characteristics of PTCs.

(2) The optical efficiency of PTC changes from 0.4 to 0.8 in a whole year. The efficiency first decreased and then increased with the turning point of the change at noon. The highest operating efficiency in these three areas is in June. The lowest operating collector optical efficiency is in December.

(3) The shadowing losses are introduced by collector shading during approximately the first and last 90 
minutes of operation each day. The end loss factor ranged from 0.985 to 1 .

(4) The optical efficiency of PTCs is mainly influenced by the incident angle of the sun; shadowing effect and end loss effect are weak in the effect of optical efficiency.

(5) The annual optical efficiency of the parabolic trough solar collector running in Lhasa is the highest in these three areas.

The analytical method to performance simulation for the optical efficiency of solar concentrator can be applied to other concentrated solar systems. We are developing the program for performance simulation for solar tower system in China.

\section{Conflict of Interests}

The authors declare that there is no conflict of interests regarding the publication of this paper.

\section{Acknowledgments}

This study was simultaneously supported by the Key Laboratory Open Fund Project of Jiangsu Provincial Key Laboratory of Solar Energy Science and Technology (Grant no. JPKLSST201504) and the Natural Science Foundation of the Jiangsu Higher Education Institutions of China (Grant no. 14KJD470003).

\section{References}

[1] O. Behar, A. Khellaf, and K. Mohammedi, "A review of studies on central receiver solar thermal power plants," Renewable and Sustainable Energy Reviews, vol. 23, pp. 12-39, 2013.

[2] A. H. Slocum, D. S. Codd, J. Buongiorno et al., "Concentrated solar power on demand," Solar Energy, vol. 85, no. 7, pp. 15191529, 2011.

[3] H. L. Zhang, J. Baeyens, J. Degrève, and G. Cacères, "Concentrated solar power plants: review and design methodology," Renewable and Sustainable Energy Reviews, vol. 22, pp. 466-481, 2013.

[4] Office of the State Council of China, "Strategic action plan for energy development (2014-2020)," 2014, (Chinese), http://www.gov.cn/zhengce/content/2014-11/19/content_9222 .htm.

[5] Dunhuang Energy Bureau, Environmental Assessment Document for Dunhuang $10 \mathrm{MW}$ of Solar Thermal Power Generation Projects, Dunhuang Energy Bureau, 2015 (Chinese), http://www.dunhuang.gov.cn/ReadNews.asp?NewsID=16475.

[6] A. A. Hachicha, I. Rodríguez, R. Capdevila, and A. Oliva, "Heat transfer analysis and numerical simulation of a parabolic trough solar collector," Applied Energy, vol. 111, no. 11, pp. 581-592, 2013.

[7] S. A. Kalogirou, "A detailed thermal model of a parabolic trough collector receiver," Energy, vol. 48, no. 1, pp. 298-306, 2012.

[8] H. Müller-Steinhagen and F. Trieb, "Concentrating solar power'. A review of the technology," Quarterly of the Royal Academy of Engineering, no. 18, pp. 43-50, 2004.

[9] A. Fernández-García, E. Zarza, L. Valenzuela, and M. Pérez, "Parabolic-trough solar collectors and their applications,"
Renewable and Sustainable Energy Reviews, vol. 14, no. 7, pp. 1695-1721, 2010.

[10] W. Jinping, W. Jun, Z. Yaoming, and B. Xiaolong, "Analysis of heat transfer characteristics for parabolic trough solar collector," Transactions of the Chinese Society of Agricultural Engineering, vol. 31, no. 7, pp. 185-192, 2015 (Chinese).

[11] K. M. Knight, S. A. Klein, and J. A. Duffie, "A methodology for the synthesis of hourly weather data," Solar Energy, vol. 46, no. 2, pp. 109-120, 1991.

[12] M. Petrakis, H. D. Kambezidis, S. Lykoudis et al., "Generation of a 'typical meteorological year' for Nicosia, Cyprus," Renewable Energy, vol. 13, no. 3, pp. 381-388, 1998.

[13] G. Florides, S. Kalogirou, K. Theophilou et al., "Analysis of the typical meteorological year (TMY) of Cyprus and house load simulation," in Proceedings of the 8th International IBPSA Conference, Eindhoven, The Netherlands, 2003.

[14] J. García-Barberena, P. Garcia, M. Sanchez et al., "Analysis of the influence of operational strategies in plant performance using SimulCET, simulation software for parabolic trough power plants," Solar Energy, vol. 86, no. 1, pp. 53-63, 2012.

[15] J. Bonilla, L. J. Yebra, S. Dormido, and E. Zarza, "Parabolictrough solar thermal power plant simulation scheme, multiobjective genetic algorithm calibration and validation," Solar Energy, vol. 86, no. 1, pp. 531-540, 2012.

[16] P. H. Wagner and M. Wittmann, "Influence of different operation strategies on transient solar thermal power plant simulation models with molten salt as heat transfer fluid," Energy Procedia, vol. 49, pp. 1652-1663, 2012.

[17] W. Huang, P. Hu, and Z. Chen, "Performance simulation of a parabolic trough solar collector," Solar Energy, vol. 86, no. 2, pp. 746-755, 2012.

[18] X. Zhang, W. Xu, T. He et al., "Solar thermal system evaluation in China," International Journal of Photoenergy, vol. 2015, Article ID 163808, 12 pages, 2015.

[19] W. B. Stine and R. W. Harrigan, Solar Energy Fundamentals and Design: With Computer Applications, John Wiley \& Sons, Hoboken, NJ, USA, 1985.

[20] W. Jinping, W. Jun, F. Wei, W. Dengwen, and Z. Yaoming, "Development and application of sun-tracking control system for parabolic trough solar collector," Transactions of the Chinese Society of Agricultural Engineering, vol. 31, no. 2, pp. 45-52, 2015.

[21] R. Dhanabal, V. Bharathi, R. Ranjitha, A. Ponni, S. Deepthi, and P. Mageshkannan, "Comparison of efficiencies of solar tracker systems with static panel single-axis tracking system and dualaxis tracking system with fixed mount," International Journal of Engineering \& Technology, vol. 5, no. 2, pp. 1925-1933, 2013.

[22] C. K. Pandey and A. K. Katiyar, "A note on diffuse solar radiation on a tilted surface," Energy, vol. 34, no. 11, pp. 1764-1769, 2009.

[23] G. Morin, J. Dersch, W. Platzer, M. Eck, and A. Häberle, "Comparison of linear Fresnel and parabolic trough collector power plants," Solar Energy, vol. 86, no. 1, pp. 1-12, 2012.

[24] K. J. Riffelmann, "Comparison between PTR70 and UVAC: efficiency tests, thermal loss measurements and Raytracing experiments," Status Seminar, vol. 1, no. 7, pp. 187-197, 2005.

[25] F. Lippke, "Simulation of the part load behaviour of a 30 MW SEGS plant," Tech. Rep. SAND95-1293, Sandia National Laboratories, Albuquerque, NM, USA, 1995.

[26] V. Dudley, G. Kolb, M. Sloan, and D. Kearney, "SEGS LS2 solar collector test results," Tech. Rep. SAND94-1884, Sandia National Laboratories, Albuquerque, NM, USA, 1994. 
[27] M. J. Wagner and P. Gilman, “Technical manual for the SAM physical trough model," Tech. Rep., Sandia National Laboratories, Albuquerque, NM, USA, 2011.

[28] A. M. Patnode, Simulation and performance evaluation of parabolic trough solar power plants [Diss.], University of Wisconsin-Madison, Madison, Wis, USA, 2006.

[29] J. Duffie and W. Beckman, Solar Engineering of Thermal Processes, John Wiley \& Sons, Hoboken, NJ, USA, 3rd edition, 2006.

[30] M. Ibáñez Plana, J. Rosell Polo, and J. I. Rosell Urrutia, Tecnología Solar, Ediciones Mundi-Prensa, Madrid, Spain, 2005.

[31] B. Bourges, "Improvement in solar declination computation," Solar Energy, vol. 35, no. 4, pp. 367-369, 1985.

[32] http://www.nrel.gov/csp/solarpaces/project_detail.cfm/ projectID $=33$. 

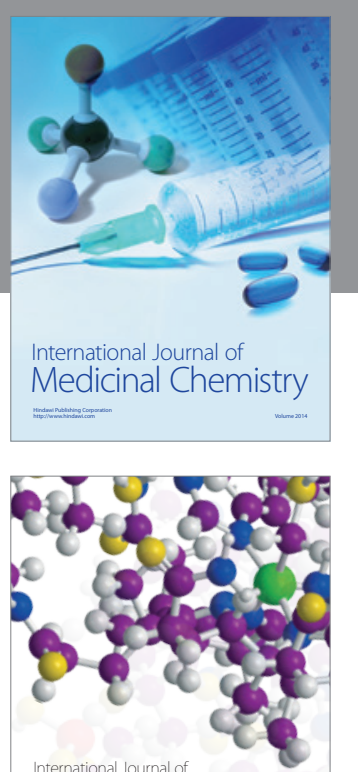

Carbohydrate Chemistry

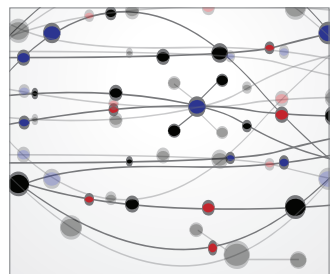

The Scientific World Journal
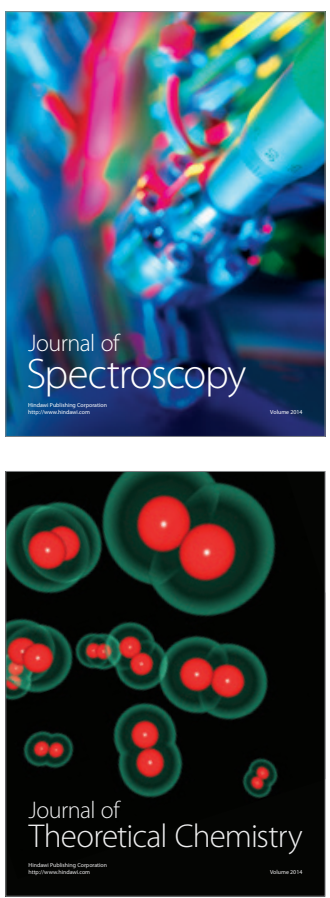
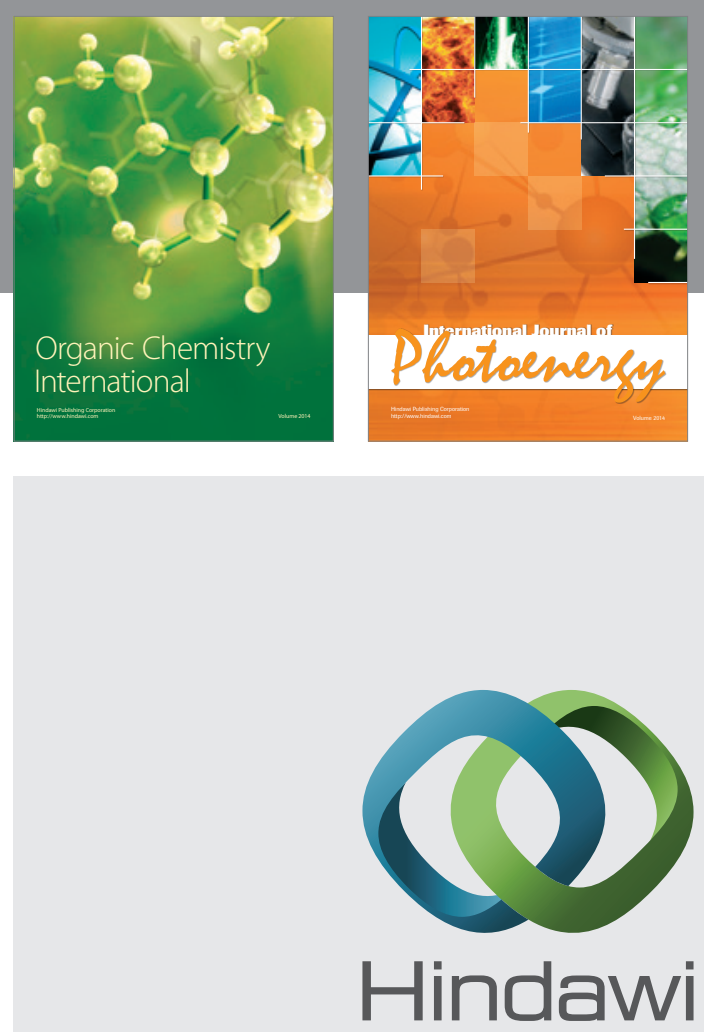

Submit your manuscripts at

http://www.hindawi.com

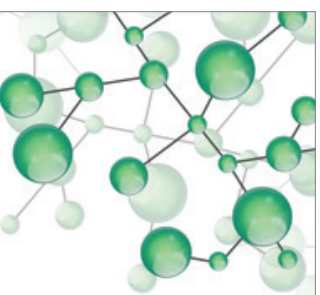

International Journal of

Inorganic Chemistry

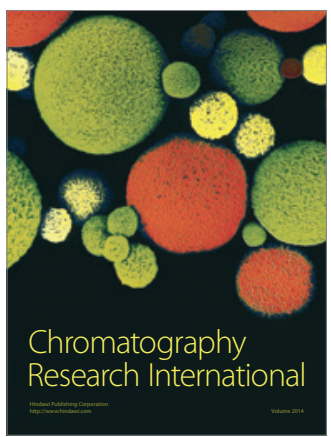

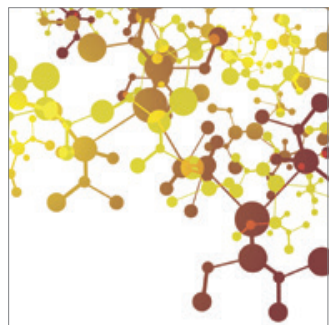

Applied Chemistry
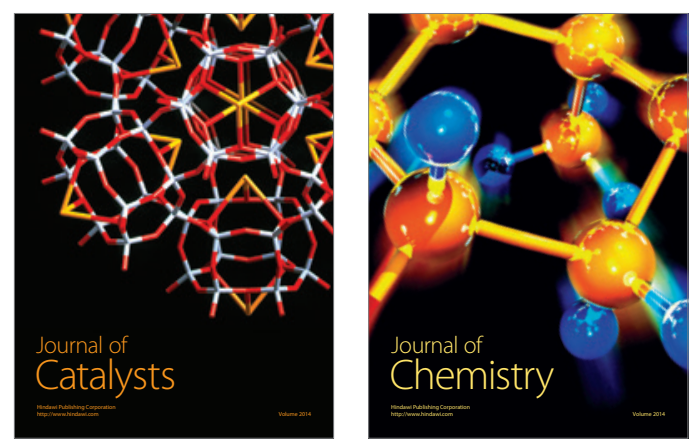
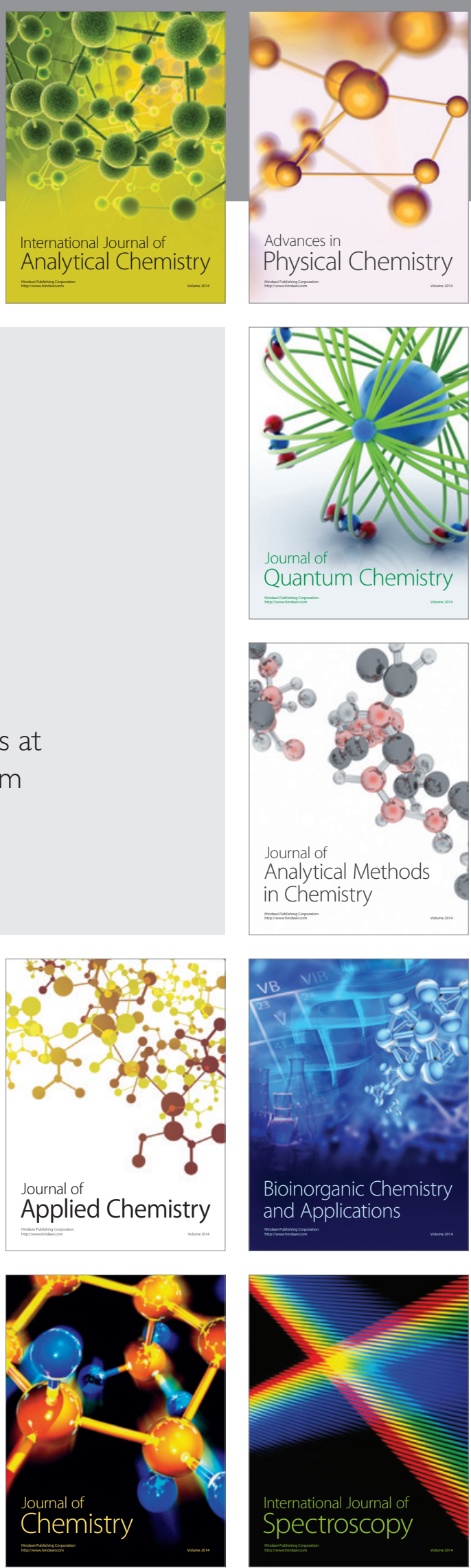